\title{
Ageing, Social Distancing, and COVID-19 Risk: Who is more Vulnerable?
}

\author{
Jamshid Faraji ${ }^{1,2}$, Gerlinde A.S. Metz ${ }^{1 *}$ \\ ${ }^{1}$ Canadian Centre for Behavioural Neuroscience, University of Lethbridge, Lethbridge, AB, \\ Canada \\ ${ }^{2}$ Faculty of Nursing \& Midwifery, Golestan University of Medical Sciences, Gorgan, Iran
}

Number of Pages for Body Text: 24

Number of Figures: 3

Number of Words in Abstract: 155

\section{*Corresponding Author:}

Gerlinde A.S. Metz, PhD

Canadian Centre for Behavioural Neuroscience

University of Lethbridge

4401 University Drive

Lethbridge, Alberta T1K 3M4

Canada

Email:gerlinde.metz@uleth.ca 


\begin{abstract}
Perceived social support represents an important predictor of healthy ageing. The global COVID-19 pandemic has dramatically changed the face of social relationships and exposed elderly as a particularly vulnerable population. Social distancing may represent a double-edged sword for older adults, protecting them against COVID-19 infection while also sacrificing personal interaction and attention at a critical time. Here, we consider the moderating role of social relationships as a potential influence on stress resilience, allostatic load, and vulnerability to infection and adverse health outcomes in the elderly population. Understanding the mechanisms how social support enhances resilience to stress and promotes mental and physical health into old age will enable new preventive strategies. Targeted social interventions may provide effective relief from the impact of COVID-19-related isolation and loneliness. In this regard, a pandemic may also offer a window of opportunity for raising awareness and mobilizing resources for new strategies that help build resilience for our ageing population and future generations.
\end{abstract}

Keywords: COVID-19, novel coronavirus, social distancing, physical distancing, lockdown, confinement, social isolation, nursing homes, ageing, two-hit model, allostasis, allostatic load 
"If you're old, don't try to change yourself, change your environment."

\author{
B.F. Skinner
}

The novel coronavirus disease 2019, SARS-CoV-2 or COVID-19, is now recognized as one of the most contagious human viral infections. It gave rise to a global pandemic and a global health emergency with dramatic, still unpredictable social and economic long-term consequences for our society. Elderly individuals seem to be particularly vulnerable to developing severe COVID-19 infection, with higher risk of morbidity and mortality than any other age group (Onder et al., 2020; Protection, 2020). Fatalities in the general population were significantly reduced by rapid social engineering and early preventative policies imposed by governments and health officials around the world, including travel restrictions, curfews and social-physical distancing (Flaxman et al., 2020; Hsiang et al., 2020). Nevertheless, population-based patterns of adverse health outcomes from COVID-19 still reflect greater vulnerability in the elderly, and in long-term senior care facilities and nursing homes (Dowd et al., 2020; Verity et al., 2020).

The past century has seen an extension in life expectancy globally, almost doubling the average lifespan in Western countries (Chmielewski et al., 2016). The global ageing population is rapidly growing and in 2020 the number of individuals 60 years and older for the first time is expected to exceed the number of children and youth (Ambeskovic et al., 2017). Increased longevity is not necessarily associated with an extended healthspan, however, due to adverse cultural and lifestyle determinants and poor environmental conditions (McClintock et al., 
2016).The definition of ageing refers to a time-dependent functional decline that is typically accompanied by progressive deterioration of physiological and cellular integrity. For example, about $88 \%$ of North Americans aged 65 years and older experience significant physical and mental health decline (Ambeskovic et al., 2020) which results from accumulated cell and DNA damage acquired across the lifespan (Ambeskovic et al., 2020; Lopez-Otin et al., 2013), raising the risk of immune deficiencies, poor cardiovascular outcomes and non-communicable disease risk, cognitive and neurological impairments, and mobility problems (Lopez-Otin et al., 2013). It is therefore not unexpected that older adults are generally at greater risk of COVID-19 infection than other age groups (https://www.who.int).

Acceleration in the biological processes of cellular ageing, experiential, environmental and pathological factors may raise individual vulnerability to COVID-19 infection and severe symptoms. This is especially true for elderly individuals with chronic medical conditions like diabetes as they are reportedly at higher risk of developing severe COVID-19 complications (Guan et al., 2020; Verity et al., 2020). Based on reports of non-communicable and communicable diseases, it is possible that COVID-19 vulnerability includes adverse childhood and lifetime experiences (Danese and McEwen, 2012), heritable epigenetic markers linked to ancestral stress (Ambeskovic et al., 2019; Faraji et al., 2017b; Yao et al., 2014), environmental pollution (Chau and Wang, 2020; Hoyt et al., 2020), poor diet (Mozaffarian et al., 2019), and poor social support (Ge et al., 2017; Malcolm et al., 2019; Menec et al., 2020). Each of these factors may be considered a stressor, or a "hit", with potentially cumulative impacts (Daskalakis et al., 2013; Verstraeten et al., 2019b) on COVID-19 vulnerability and complication. Across a single lifespan, the effects of recurrent stress may accumulate (Faraji et al., 2017a), thus increasing the body's "wear and tear" and allostatic load (AL), ultimately heightening the vulnerability to disease in an older individual 
(McEwen, 2002; McEwen and Wingfield, 2010). This framework has been well operationalized to explain the origins of complex diseases, including cardiovascular (Mattei et al., 2010), kidney (Lunyera et al., 2020), lung (Beckie, 2012), psychiatric and neurological (Berger et al., 2019; Kobrosly et al., 2014; Misiak, 2019; Ullmann et al., 2019; Zsoldos et al., 2018) diseases. Experiences in older age, particularly by social experiences, add another important layer to these allostatic load considerations.

The intensity of social relationships in Western societies is generally diminishing, and elderly are particularly concerned by social isolation and feelings of loneliness (Cacioppo and Cacioppo, 2018; Yang et al., 2016). Although the definition of social isolation and loneliness varies, biological sex and gender are consistent key determinants of their prevalence in populationbased surveys. If isolation is defined as living alone, approximately $20 \%$ of elderly men and nearly $40 \%$ of elderly women in Western societies report that they feel isolated and lack social contacts (Elmer, 2018). Lack of social relationships can instigate or exacerbate stress responses (Cacioppo et al., 2011), depression and anxiety (Ge et al., 2017) and reduce the lifespan (Kikusui, 2018; Mikosz et al., 2015; Rodriguez-Artalejo et al., 2006). Individuals with weaker social relationships are $50 \%$ less likely to survive a health issue, regardless of age, initial health status or cause of death (Holt-Lunstad et al., 2010).

The nature of social relationships dramatically changes as individuals age, however. Social networks tend to narrow with increasing age, and novelty seeking, which facilitates building new social relationships, becomes reduced in old age ( peripheral members of social networks in the ageing is larger than the loss of intimate members, although both contribute to the well-being of older adults. Despite a shrinking social network 
during ageing, the need for proximity, meaningful relationships and reciprocity (Bruggencate TT, 2018) are characteristic features of social needs in late life.

The role of social experiences in health outcomes demands particular consideration with respect to the COVID-19 pandemic. During the COVID-19 pandemic, physical distancing was introduced as an effective preventative measure to reduce the risk of infection (Gatto et al., 2020). While this has significantly helped to contain the global spread of infection, it has also exacerbated the social isolation of elderly as visits of family and friends to nursing homes and long-term care facilities were prohibited to protect their residents. At all ages, the COVID-19 pandemic has increased the prevalence of negative psychological effects such as post-traumatic stress disorders (PTSD), confusion, and anger due to quarantine, fear, frustration, boredom, inadequate financial resources and supplies, and stigma (Brooks et al., 2020). Elderly individuals are particularly vulnerable to the adverse impact of these stressors, however, and thus pre-existing social isolation could be exacerbated by the pandemic.

Here, we will consider the moderating role of social relationships as a potential influence on COVID-19 vulnerability and adverse outcomes in the elderly population. The presented literature will elucidate the hypothesis that resilience of the host to SARS-CoV-2 infection and associated complications will be reduced by cumulative lifetime stress exposure. Considering that lifetime exposure to various stresses may represent the first "hit", social isolation in older age may exacerbate these effects as a second "hit" and generate a potentially harmful stress burden. We will discuss the underlying physiological mechanisms of psychosocial stress and integrate the existing literature to propose a unifying concept of the social determinants of healthy ageing and potential mitigation strategies. 


\section{SOCIAL INTERACTION: THE PRECURSOR OF PSYCHOBIOLOGICAL INTEGRITY}

Humans did not evolve to be alone (Cacioppo and Cacioppo, 2014). Influenced by Aristotle's famous aphorism, it is frequently being posited that, by nature, we are social animals, tautologically meaning that we tend to live with others and enjoy social interactions because we are inherently social beings. Reflections of social life in human biology and brain development (Hari et al., 2015; Richardson et al., 2018; Schmalzle et al., 2017), however, go beyond the limits of such equivocal notions. In fact, humans interact with others across the lifespan, and at the same time also influence others while accepting influences from them. This reciprocal influence of social life brings about changes at different levels (i.e., attitudes, motivations, beliefs and behaviours) (Kelman, 1958). The human brain is highly attuned to social interactions between multiple elements (Isik et al., 2017), and evolved to perceive and appraise social interactions already starting during prenatal development (Evertz et al., 2020), reflecting biological adaptation ( et al., 2007). Social interactions occur along a continuum ranging from full engagement in social communication to a complete disengagement from social ties (social isolation) and supports. Social supports, in theoretical models, encompass two important quantitative and qualitative dimensions. Quantitative (structural) aspects of social support include social interaction, which is measured in terms of the quantity of friends and relatives as well as frequency of social interactions an individual reports. Social support also can be measured qualitatively or functionally through evaluating the quality of emotional (receiving love, acceptance and empathy) or instrumental (practical help) supports (Cohen, 2004). Both components of social interaction are reflected by objective biological parameters of health and longevity (Uchino et al., 2012).

Psychological processes that contribute to healthy ageing via social interactions appear to exert protective functions against maladaptive physical disease states (Kikusui, 2018; $\underline{\text { Rodriguez- }}$ 
Artalejo et al., 2006). Although a detailed review of research over the impact of the quality and quantity of social life in the elderly is outside the scope of this perspective, two important points need to be addressed. First, social relationships, depending upon their cultural determinants and conceptualization, are multidimensional, and thus their links to health (particularly in senescence) are multifaceted. Since the impact of social interaction on health outcomes is generally dependent upon multiple layers of society (e.g. family, friends, colleagues, organizations, and community) (Sippel, 2015b), there is continuous need for extensive policy reform or reconceptualization aimed at improving social atmosphere and systems for ageing populations. Second, social interaction per se does not necessarily guarantee health promotion. Investigations are mainly focusing on understanding and characterizing the dynamics underlying positive social interaction whereas its negative face is largely ignored, particularly by mainstream gerontological research. Negative interactions may entail unpleasant social encounters that are characterized by the lack of reciprocity, criticism and rejection (Krause and Rook, 2003), or discouraging the expression of feeling and failing to provide promised help (Lincoln, 2000). Although both aversive and positive (facilitating) social interactions are fundamental influences on brain and behaviour (Beery and Kaufer, 2015), arguably only meaningful positive social interactions impart benefits for health.

Positive interactions between individuals in a social network (Reblin and Uchino, 2008) may improve the quality of life and alleviate existing health complications. Potential mitigating mechanisms include reduced pro-inflammatory processes (Yang et al., 2014) and dampened hormonal stress responses (Hostinar et al., 2014) along with other changes in biophysiological mechanisms (Boen et al., 2018). Psychologically, social integration provides informational and emotional resources that promote adaptive behavioural responses (e.g. self-disclosure) to stressful experiences such as diseases and trauma ( 
buffering their deleterious impact on health, or shaping health behaviours (Sippel, 2015a). It seems that when these psychosocial resources are available, individuals experience an enriched opportunity to reciprocally share emotions and optimize their coping skills. Sharing the emotional burden of stress may provide relief for the afflicted, but it may also generate bystander stress for their receiving social contacts (Mychasiuk et al., 2011).

The nature of social relationships changes during the lifespan. Ageing in particular may be accompanied by social disengagement or withdrawal (Elaine Cumming, 1960) driven by the hegemony of emerging new needs and priorities. The need for a new equilibrium between the social needs of an ageing individual and their environment may gradually alter the existing social relationship (Shaw et al., 2007) and may result in greater physical distance than what existed in the middle age (Tobin and Neugarten, 1961). Accordingly, social ties in ageing adults are closely linked to a variety of challenges such as physical disabilities (Manini, 2011; Mendes de Leon et al., 1999; Molton and Yorkston, 2017), chronic-neurodegenerative diseases ( and Sakellariou, 2020), health risks (Boen et al., 2012; Edwards et al., 2017; Lindsay Smith et al., 2017), negative psychological states (Boen et al., 2012; Gronning et al., 2018; Matt and Dean, 1993), as well as morbidity and mortality (Boyle et al., 2009; Eng et al., 2002; Steptoe et al., 2013). Consequently, the nature of social relationships in aged individuals may predict mortality (Gronewold et al., 2020; Holt-Lunstad et al., 2010; House et al., 1988). As summarized in Figure 1, a strong social network and available support, alternatively, provides adults with the prospect of successful ageing (Lerner R.M., 2013; Musich et al., 2018).

Interestingly, it appears that males and females, both human and animal, respond differently to social interactions (Faraji et al., 2018b). These differences in response to social cues may range from changes in neurobiological measures and processes (Cherif et al., 2003; Mikosz et al., 2015; 
Ngun et al., 2011; Stack et al., 2010) to displaying distinctive sex- and gender-specific behaviours

(Faraji et al., 2018b; Palchykov et al., 2012; Szell and Thurner, 2013; Trainor et al., 2011) across

the life course.

CORE INFERENCES: LESSONS FROM LITERATURE

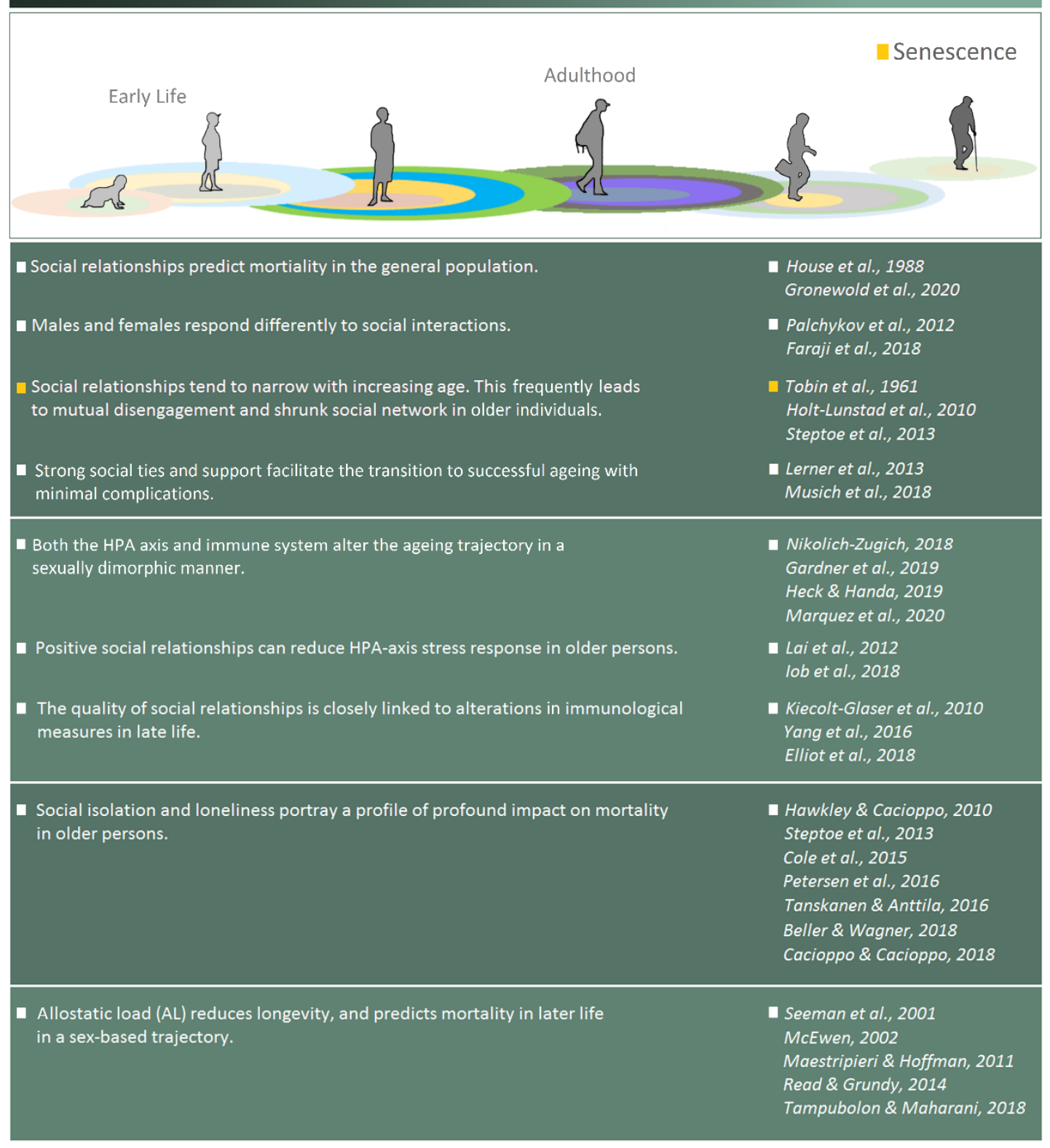

Figure 1: Overview of relevant literature that discussed link social support, stress response and/or immune status to the chance $s$ of healthy ageing. 
Sharply different levels and lifetime profiles of sex hormones (e.g. androgens and estrogens) lead to striking differences between male and female behaviours (Choleris et al., 2018; Zethraeus et al., 2009). Of all sex-related behavioural disparities, sex differences in social behaviour is one of the most pronounced. Major aspects of sex differences in social interaction may be explained by the response to oxytocin (OT), an evolutionarily conserved neuropeptide which is critically involved in social bonding, cognition and improved coping with stress (Caldwell, 2018; Grewen and Light, 2011). For instance, females appear more vulnerable than males to genetic and behavioural changes when the secretion of endogenous oxytocin in response to social life is interrupted (Faraji et al., 2018a). Also, oxytocin may facilitate various forms of prosocial behaviours, building trust and enhancing sociality in humans and non-human animals (Holt-Lunstad et al., 2015; Kreuder et al., 2020; Ma et al., 2016; Mottolese et al., 2014; Olff et al., 2013; Rimmele et al., 2009; Theodoridou et al., 2009), an effect that would presumably enhance social engagement (Figure 2). The interaction between oxytocin and sex hormones, especially estrogens, also appear to impact social recognition and regulate social learning (Choleris et al., 2012; Gabor et al., 2012), the main foundations of a social interactions. While the first enables an individual to distinguish between conspecifics and to establish close social relationships with a familiar being, the latter provides a process through which the individual learns to observe a conspecific and/or decide how to interact with others.

In line with what has previously been established in female rodents (Choleris et al., 2003), estrogenic receptor (ESR1 and ESR2) signals may regulate social recognition in women (Karlsson et al., 2016). Androgens, on the other hand, may play a role in the male-biased function of neural circuits that develop specialized roles in social relationships (Lombardo et al., 2018). For example, testosterone, a primary male sex hormone that works directly via the androgen receptor (AR) and 
is known as an inhibitor of sociality, significantly decreases interpersonal trust when administered to females (Bos et al., 2010). In addition to the endocrine pathways, social interactions affect
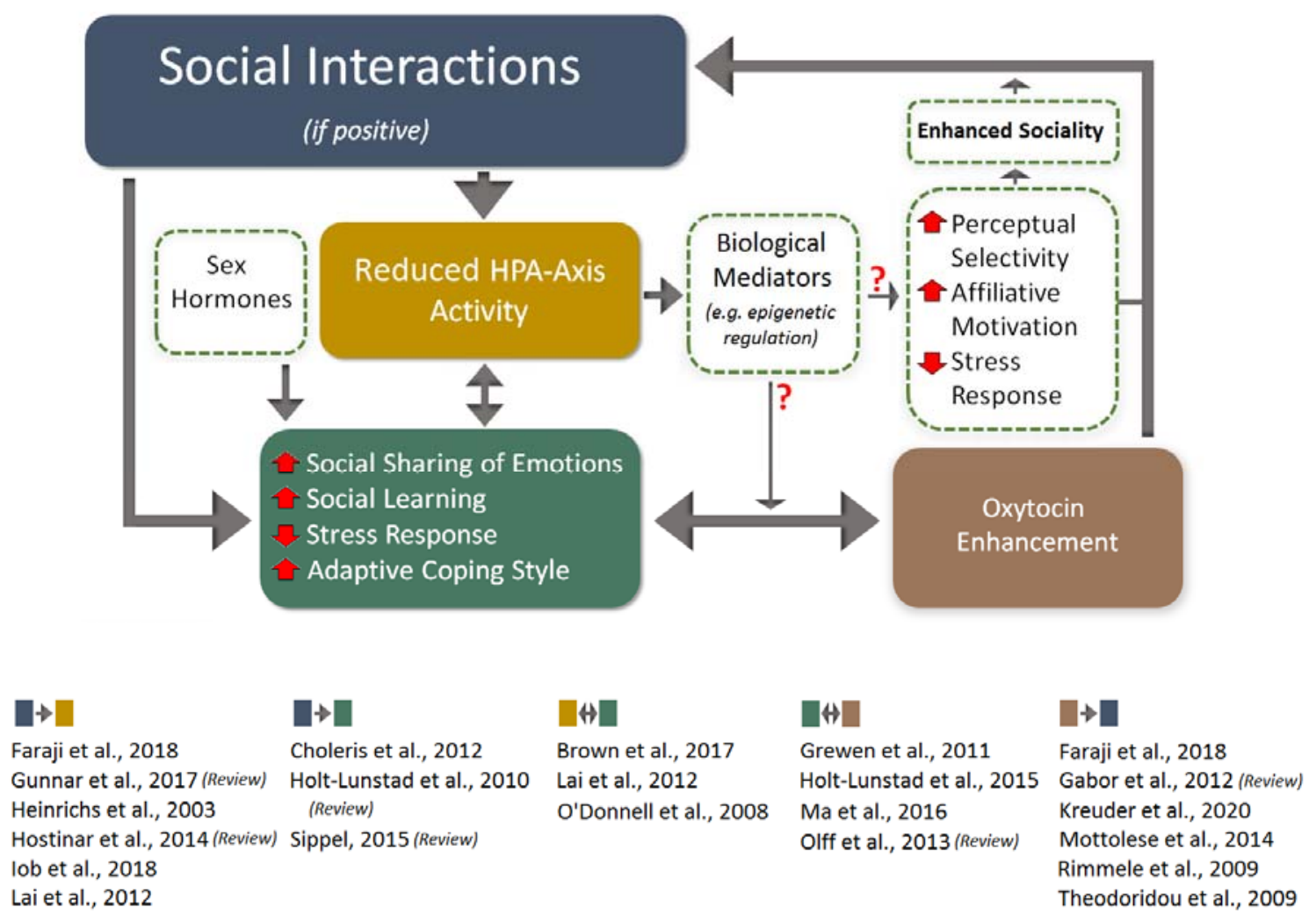

Figure 2: Representation of hypothetical mechanisms that potential affect the impact of social relationships in humans. Positive social relationships are characterized by reduced HPA axis activity, which translate into positive emotions in a sex-dependent manner. Via biological mediators, such as epigenetic regulation, and via expression of the peptide hormone oxytocin, both the HPA axis and the positive emotional state will affect the resilience, coping and mental wellbeing, and ultimately promote healthy ageing and longevity.

human development and ageing also via the major biological domains of the hypothalamicpituitary-adrenocortical (HPA) axis and the immune system. 
Hypothalamic-Pituitary-Adrenal (HPA) Axis Activity and Social Interaction. A general assumption is that there are functional perturbations with advancing age that result in dysfunctional activity of various endocrine glands and their target organs (Gardner et al., 2019; Yiallouris et al., 2019). These hormonal challenges in the elderly also may interfere with hormonal crosscommunication between various endocrine axes. Accordingly, the neuroendocrine theory of ageing (Diamanti-Kandarakis et al., 2017; Toescu, 2013) refers to the consequences of age-related changes in the HPA axis, the key adaptive neuroendocrine system that responds to stress. Cumulative evidence from human and non-human studies suggest that the HPA axis is altered by ageing (Aguilera, 2011; Gardner et al., 2019; Giordano et al., 2005; Goncharova et al., 2019; Gust et al., 2000; Meaney et al., 1992). The HPA axis is also subject to diurnal variation and represents a neurohormonal hallmark of emotionality in humans and animals (Faraji et al., 2018b; $\underline{\text { Metz, }}$ 2007). HPA-axis activity is characterized by prominent sex differences as females initiate it more rapidly in response to stress and produce a greater output of stress hormones (Goel et al., 2014; Heck and Handa, 2019; Kokras et al., 2019). In general, sex differences in HPA-axis activity are evident already early in life (Slotkin et al., 2008; van der Voorn et al., 2017) and reveal higher baseline glucocorticoid (GC) levels and higher absolute GC concentrations during stress in females than males. GC levels also remain elevated for longer in females, suggesting an increased stress reactivity in females along with reduced negative feedback. Importantly, when long-term stress exposure (e.g. disease, trauma, isolation and loneliness) is inevitable, it appears that females display more flexible and adaptive behavioural responses than males (Handa and McGivern, 2010; Oyola and Handa, 2017). Therefore, it seems justified to conclude that, influenced by the hormonal changes of menopause in women, the ageing brain also shows both sex-specific responses to stress and sex-specific capacity of building resilience. 
The activation of the HPA axis and elevated circulating GCs are essential for adaptive responses to acute and chronic stress and thus elemental for the individual's survival, even though its dysregulation is apparent during ageing. Because complications in HPA axis activity in the elderly begin with high GC levels, experimental challenges have highlighted the impaired GCmediated inhibitory (negative) feedback loop and reduced GC receptor sensitivity in the brain (Gaffey et al., 2016). Both conditions lead to prolonged HPA axis activation and a long-term elevation in GC in the ageing brain (Gaffey et al., 2016; Goncharova, 2014; Gust et al., 2000). Another key aspect of functional alterations in the ageing brain is the loss of GC receptors in the hippocampus (HPC), a sexually dimorphic structure intimately involved in learning, memory and spatial navigation. Interestingly, the hippocampus shows the highest density of corticosteroid receptors in the brain (McEwen and Sapolsky, 1995) and critically contributes to the negative feedback to the HPA axis, making sure the stress response shuts down after cessation of stress (Sapolsky, 2000; Sapolsky et al., 1986). Hence, because the hippocampal volume decreases with ageing, the consequent weakening of negative feedback may be responsible for HPA axis dysregulation and over-activity.

Although this topic falls beyond the scope of the present review, it is necessary to state that prolonged disturbances in HPA axis function are closely tied to psychophysiological pathologies in elderly, such as higher risk of cognitive decline (Csernansky et al., 2006; Ferrari et al., 2001; Ouanes and Popp, 2019), depression (Belvederi Murri et al., 2014; Iob et al., 2019), and anxiety and stress-related disorders (Hellwig and Domschke, 2019; Mantella et al., 2008). Moreover, ageing-associated HPA axis dysregulation raises the risk of cardiovascular diseases and hypertension (Burford et al., 2017), stroke (Merrett et al., 2010) and diminished immunity (Heffner, 2011). Altered HPA axis functioning in old age may also critically contribute to 
degenerative pathologies, such as Alzheimer's disease (AD) (Canet et al., 2019; Ennis et al., 2017; Ouanes and Popp, 2019) and Parkinson's disease (Smith et al., 2008). Using a mathematical model in humans, McAuley and others showed that both acute (transient) and chronic (repeated) elevations in cortisol secretion increase ageing-associated HPC atrophy and loss of hippocampal activity (McAuley et al., 2009). Even though transient activation of the HPA axis is essential for stress adaptation, prompt termination of the stress response is necessary to prevent deleterious consequences of excessive GC levels. On the other hand, the normal stress response can be profoundly impacted by chronically elevated GC levels in the elderly, leading to withdrawal and avoidance (Dickerson and Kemeny, 2004), impaired ability to recover from stressful stimuli (Yiallouris et al., 2019), and consequently accelerated ageing (Lavretsky and Newhouse, 2012).

Health-related concerns linked to an overactive HPA axis also emerge from the sexual dimorphism observed in humans (Vamvakopoulos, 1995) and non-human animals (Babb et al.., $\underline{2013}$; Faraji et al., 2018b).Females typically show more variability in HPA axis activity than males (Babb et al., 2013; Herman et al., 2016; MacLusky et al., 1996; Weiss et al., 1999). Due to prolonged GC elevation in the ageing brain, chronic stressful experiences increases the risk for stress-related pathology mostly in women (Bangasser and Valentino, 2014). Clinical efforts therefore focus on the patterns of sex- and age-related changes in HPA axis activation as well as how to reduce vulnerability to stress-related disorders during ageing (Diamanti-Kandarakis et al., 2017).

It has been widely recognized that HPA axis activity can be regulated by a socially stimulating environment (Cohen, 2004; Faraji et al., 2017b; Gunnar, 2017; Hostinar and Gunnar, 2013; McCreary et al., 2016). For instance, social relationships, if positive, can dampen HPA axis stress responses across the lifespan, from early development (Seltzer et al., 2010), throughout 
adulthood (Heinrichs et al., 2003) and into old age (Iob et al., 2018; Lai et al., 2012). Importantly, elderly individuals who are more involved in developing and strengthening their social relationships show more effective activation and deactivation of the HPA axis (Lai et al., 2012). The stress-buffering effect of social relationships was also explored in rodents with results that have been reliably consistent with clinical findings (Hostinar et al., 2014). Prolonged social experiences in rats may form new biobehavioural phenotypes such as reduced HPA axis activity, not only in directly exposed individuals, but also in their unexposed (non-social) descendants in a sexually dimorphic manner (Faraji et al., 2018b). Social enrichment in animals promotes expression of glucocorticoid receptors (Noorlander et al., 2006) and mineralocorticoid receptors (DeVries et al., 2003) in the brain, thus enhancing effective HPA axis regulation and negative feedback function.

Immune System Function and Social Interaction. Older adults are at higher risk for COVID19 complications than the younger populations, partially due to a weaker immune system and potentially other pre-existing health conditions (Yuan et al., 2020). Ageing is associated with profound physiological changes that also affect the immune system, a complex host defense system that protects the organism from pathogens, either internal or external. Immune changes with ageing, commonly known as immunosenescence, mainly involve a decline in many immune parameters when compared to young healthy individuals (Aiello et al., 2019). The immunosenescence and a chronic low-grade inflammation called inflamm-ageing (Franceschi et al., 2000; Fulop et al., 2017) stand together at the origin of most diseases of the elderly. The agerelated immune decline typically refers to the gradual deterioration, profound remodeling and alterations of immune function with major impact on health and survival during senescence (Aiello et al., 2019; Fulop et al., 2017; Jiang et al., 2013). 
The immune system, which acts in close dialogue with the neuroendocrine system including the HPA axis (Bellavance and Rivest, 2014), also exhibits significant sex-specific differences (Giefing-Kröll et al., 2015; Márquez et al., 2020). Aside from age-specific changes in immune function, men and women also respond differently to invading pathogens. This sexual dimorphism in immune response may have a serious impact on, for instance, the magnitude of inflammatory responses and pathogenesis of many infectious diseases that are a major cause of mortality among older adults. An increase in inflammatory pathways and immune-mediating genes and a decline in B-cell specific loci has recently been reported in older males (Márquez et al., 2020) which suggests an accelerated inflamm-ageing trajectory in ageing men. At comparable exposure levels, men also seem to be more susceptible to infections caused by viruses, bacteria, parasites, and fungi (GuerraSilveira and Abad-Franch, 2013). Hence, sexually dimorphic susceptibility to inflamm-ageing and infectious diseases, along with dysregulated adaptive immunity and increased systemic inflammation in the elderly, require careful consideration in age-specific interventions and therapies.

The molecular and cellular foundations of immunosenescence are still unknown. A growing body of evidence, however, has attributed the age-related immune decline to overproduction of pro-inflammatory cytokines such as interleukin $1 \beta$ (IL-1 $\beta$ ), interleukin 6 (IL-6), interleukin 18 (IL18), C-reactive protein (CRP), and tumour necrosis factor alpha (TNFa) in the innate immune system (de Almeida Roediger et al., 2019; Del Giudice and Gangestad, 2018; Koelman et al., 2019; Maggio et al., 2006; Ng et al., 2018; Rea et al., 2018; Ventura et al., 2017). Specifically, increased production of IL-6, a key pro-inflammatory cytokine, appears to be associated with a range of immune-mediated conditions in the elderly including rheumatoid arthritis, osteoporosis, atherosclerosis, type 2 diabetes, cardiovascular disease, $\mathrm{AD}$, some forms of cancers, and frailty 
(Edwards and Williams, 2010; Krabbe et al., 2004; Lippitz and Harris, 2016; Papanicolaou et al., 1998; Pedersen et al., 2003; Rea et al., 2018; Rong et al., 2018). Recently, it was shown that elevated cortisol and plasma CRP levels in a large sample of older adults were associated with more persistent depressive symptoms over a 14-year period (Iob et al., 2020). These ageing-related diseases occur in an inextricable relation to inflammation and HPA axis dysregulation, and may enhance general disability (Ferrucci et al., 1999) and mortality among older adults ( 1999; Lee et al., 2012). In turn, good overall health in old age may be the direct consequence of a low pro-inflammatory state (Papanicolaou et al., 1998). However, the ageing phenotype, including immunosenescence and its immunological correlates, although unavoidable, may be mitigated through psychological interventions that support immune function and healthy ageing.

Immune changes that occur during the ageing trajectory are not uniform, however, involving down-regulation of some functions and up-regulation of others. Whether immune functions increase or decrease during ageing depends also on psychological influences (Bauer, 2005;

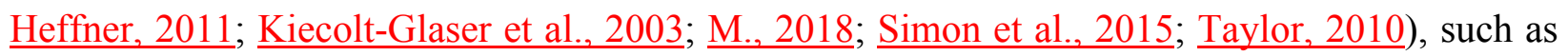
positive social interactions that may promote healthy ageing. A growing body of literature has linked alterations of inflammatory measures in late life to the quality of social connectedness (Kiecolt-Glaser et al., 2010; Loucks et al., 2006a; Loucks et al., 2006b; Yang et al., 2016). It was suggested that perceived positive relationships and social integration may be associated with lower IL-6 and higher CRP in older adults, particularly in women (Elliot et al., 2018). It should be pointed out that the association between CRP and social relationships is still lacking consistency (Loucks et al., 2006b), arguably due to differences in sociocultural structures (Glei et al., 2012). Although inflammatory markers in both sexes appear susceptible to the quality of social relationships (Yang et al., 2016), social support in particular can reduce IL-6, especially in older women (Elliot et al., 
2018). In general, it seems that structural dimensions of social connectedness are more related to inflammation (particularly CRP) in older men, whereas functional dimensions of social relationships have an impact on inflammation (particularly IL-6) in older women (Elliot et al., 2018; Friedman et al., 2005).

\section{SOCIAL-PHYSICAL DISTANCING AND ISOLATION: SOLUTION OR PROBLEM?}

In spring 2020, health agencies and governments around the globe have recommended lockdown and physical distancing in order to contain the spread of COVID-19. These measures have been widely successful in epidemic control by limiting the exposure to the general population and reduced (by 45\%) COVID-19 transmission and associated long-term health risks (for instance, see (Gatto et al., 2020)) and significantly reduced fatality (Flaxman et al., 2020). At the same time, others have cautioned that physical distancing and confinement may also exacerbate existing social issues. For example, Michael Levitt, a Nobel laureate biophysicist at Stanford University, has challenged that "lockdown [for COVID-19] caused more deaths than it saved" through "social damage - domestic abuse, divorces, alcoholism" in an interview with the Telegraph on May $23^{\text {rd }}$, 2020 (https://www.telegraph.co.uk/news/2020/05/23/lockdown-saved-no-lives-may-have-cost-nobelprize-winner-believes/). The period of physical distancing during COVID-19 may have therefore exposed the most vulnerable individuals and populations, and revealed where social support and interventions are most urgently required.

Elderly people are among the most vulnerable individuals of our society. As people age, they become increasingly susceptible to adverse consequences of social-physical distancing and withdrawal. This may lead to gradual reduction in elderly individuals interacting with their social 
environment, thus shrinking their social network. Also, a growing global gender gap in the proportion of elders (over 60 ) who reside alone ( $17 \%$ of women vs. $9 \%$ of men) has been reported (DESA, 2017). In the USA, nearly every second woman (45\%) aged 75 and over lived alone in 2017, and approximately 28\% (9.3 million women, 4.5 million men) of non-institutionalized older individuals lived alone, unveiling a hidden sex-specific trend of social disengagement and loneliness in ageing (https://acl.gov) (Aging-AoA-, 2017). Yet, by implementing social contact restrictions, the rapidly evolved COVID-19 outbreak has further changed the conventional faces of social communication for all ages throughout the world (Protection, 2020). Older adults have been especially affected by this double-edged sword; on one hand, this vulnerable group was better protected against COVID-19 risks, on the other hand, they lost important face-to-face interaction and personal attention at a time when support was critically needed. Thus, the COVID-19 pandemic may particularly affect older adults who are dependent on care. Contact restrictions during a pandemic therefore have the potential to generate the perception of social isolation and loneliness, which may raise the susceptibility to further long-term mental and physical health challenges. Moreover, events such as shrinking economic resources, mobility impairment, and the death of relatives or friends may reduce the size of a social network during ageing, and consequently accelerate age-related health problems (Bassuk et al., 1999; Cacioppo and Cacioppo, 2014; Grant et al., 2009; Heffner et al., 2011; Loucks et al., 2006a; Malcolm et al., 2019).

Social isolation is typically referred to an objective state of reduced social contact and networking (Steptoe et al., 2013) or disengagement from social ties and participation (Pantell et al., 2013), mostly due to environmental restrictions or physical demands (Valtorta and Hanratty, 2012). In fact, when experiencing social isolation, an individual lacks a sense of belonging or engagement with others (Nicholson, 2012). Social isolation represents the quantitative absence of 
social connectedness, whereas loneliness is the extent to which an individual subjectively (or emotionally) feels himself or herself socially isolated even when among other people (Cacioppo and Cacioppo, 2018; Ge et al., 2017; Hawkley and Cacioppo, 2010). Loneliness, although conceptually distinct from social isolation, represents the psychological embodiment of social isolation (Steptoe et al., 2013). It is noteworthy that "being alone" and "feeling alone" should not be confused (Cacioppo et al., 2015), even though both appear to be common problems of old age. Biological responses to stress may increase physical susceptibility (e.g., via dysregulation of the HPA axis and/or immunity) to psychological difficulties and ultimately disease, thus targeted interventions to mitigate social isolation and loneliness can significantly improve quality of life and long-term health outcomes (McLennan and Ulijaszek, 2018).

The concept of social isolation and loneliness portray a profile of profound impact on mortality in older adults, either synergistically (Beller and Wagner, 2018; Petersen et al., 2016) or independently (Coyle and Dugan, 2012; Tanskanen and Anttila, 2016). Also, it seems that each involves a distinct pathway through which they influence health risk factors (Cole et al., 2015; Hawkley and Cacioppo, 2010; Steptoe et al., 2013). While social isolation is linked to physical or general health, the loneliness has an impact on mental health (Cornwell and Waite, 2009; Coyle and Dugan, 2012; Heinrich and Gullone, 2006). Thus, health practitioners need to consider and assess social isolation and loneliness simultaneously, even though interventions for social isolation appear to be very different from interventions against the feeling of loneliness.

Aside from correlational investigations linking social exposure to psychophysiological health in later life (Iob et al., 2018; Niu et al., 2020; Steptoe and Fancourt, 2019; Uchino et al., 2012; Yang et al., 2016; Yang et al., 2014), a wide range of socially supportive interventions have also been utilized to effectively tackle social isolation and loneliness, thus reducing their 
deleterious impact on health outcomes (Alaviani et al., 2015; Banks et al., 2008; $\underline{\text { Heo et al., 2015; }}$ Saito et al., 2012; Tsai et al., 2010; Zamir et al., 2018). Although these efforts have been shown to promote social engagement, interventions that focus merely on building social networks often fail to mitigate perceived social isolation (Cacioppo et al., 2015). Healthcare providers should be aware that there is no one-size-fits-all approach for addressing social isolation and loneliness. Instead, any intervention to mitigate their harmful consequences necessitates a precise assessment of personal needs, taking into account their gender, ethnicity and culture and the intensity of isolation or loneliness experienced (Fakoya et al., 2020).

Even if health professionals and policy makers consistently follow up with the above concerns, there are also further complications that need to be seriously addressed. For one, social isolation and loneliness in later life represent a geo-specific dynamic impact on health and regional interplay, most likely due to the influence of sociocultural determinants. While these two are not highly correlated in the USA and UK (Coyle and Dugan, 2012; Steptoe et al., 2013), and with no synergistic effect in Finland (Tanskanen and Anttila, 2016), both have been closely interacting in relation to mortality in Germany (Beller and Wagner, 2018). In addition, compared with loneliness, efforts to reduce social isolation are likely to be more relevant and to have greater benefits in terms of mortality in UK (Elovainio et al., 2017; Steptoe et al., 2013), but having fairly opposite effects in the USA (Cacioppo and Cacioppo, 2018). In the Netherlands, conversely, only loneliness was found to be a major risk factor for increased mortality in older individuals, and more men than women who felt lonely died during a 10-year follow-up (Holwerda et al., 2012). However, this disparity may be generated by differences in assessment policy and monitoring, along with variations in conceptualization of social isolation and loneliness across cultures and societies. Interventions tailored to identifying and ameliorating the harmful consequences of social isolation 
and loneliness must contemplate not only how to conceptualize and measure them, but also the normative values of the respective community and cultural framework that typically determine the purpose and meaning of life in older people (Bantry-White et al., 2018). More importantly, the most effective interventions imply adaptability of the intervention to a local context within a community development approach (Gardiner et al., 2018). Practitioners and policy makers, therefore, need to ensure that they understand respective community and culture, and form a context-sensitive intervention in tackling social isolation and loneliness in later life.

\section{AGEING, SOCIAL DISTANCING, AND COVID-19: THE TWO-HIT MODEL OF STRESS}

In addition to cultural measures, the individual's past experiences and even that from previous generations may generate complex interaction and synergies with the biological ageing process and social life (Ambeskovic et al., 2020; Brown et al., 2017; Faraji et al., 2017a). Also, this relationship is strongly influenced by pre-existing health conditions, gender, personality and culture (Hajek and König, 2019; Ormstad et al., 2020; Ward et al., 2018).

Stress, in this review, refers to endocrine and behavioural responses to stressors that perturb homeostasis in a number of physiological systems (e.g., anxiety, body temperature, osmolarity, oxygen tension) (Faraji and Metz, 2020; Juster et al., 2010). The suite of these responses is essential to survival, but may not necessarily adapt the organism to its environment. Responses to repeated stress, however, are intended to maintain homeostasis by maximising adaptability, resilience, or allostasis. Allostasis mediated by the immune system, autonomic nervous system (ANS) and the HPA axis refers to a process through which the body adaptively changes to maintain stability in the face of stressors (e.g. diseases, insults, hazards, injuries etc.) (Juster et al., 2010; 
McEwen, 2002). Allostatic responses to repeated stressors, although advantageous in the short run, impose a cost for adaptation: chronic allostatic activation results in a permanent physiological shift with abnormal vital values when stress hormones and inflammatory mediators are frequently mobilised in the attempt to maintain homeostasis and maximise resilience.

Allostatic load (AL), in contrast, reflects the body's "wear and tear" when the mediators of allostasis fail to promote resilience but rather accumulate the biological burden associated with repeated stressful hits (Olson et al., 2015). Notably, the ageing trajectory reflects the cumulative impact of wear and tear previous ancestral, prenatal and lifetime psychological, physical and inflammatory stressors, with each stress representing a "hit" (Olson et al., 2015; Verstraeten et al., 2019a; Verstraeten et al., 2019b). High AL or unproductive resilience to stressors with cumulative wear and tear induced by multiple stress hits seems a hallmark of ageing in a gender-based trajectory (Seeman et al., 2001; Tampubolon and Maharani, 2018), reduces longevity (Maestripieri and Hoffman, 2011), and ultimately predicts frailty, morbidity and mortality (Read and Grundy, 2014). Moreover, stress-associated immune modulation may also increase the risk of infectious diseases in elderly (Böbel et al., 2018), and these health outcomes may be exacerbated by stress induced through social isolation or loneliness.

Cumulative wear and tear by recurrent stresses may raise the risk of age-related physiological complications and the susceptibility to adverse health outcomes (Nikolich-Žugich, 2018). Loss of social relationships and confinement during a pandemic may further challenge the psychophysiological resilience in elderly (Yang et al., 2016) and reduce the protective benefit that comes with social enrichment (O'Donnell et al., 2008; Yang et al., 2014). Each of these stressors may represent a hit that challenges the delicate balance between allostatic mediators of the stress response such as adrenal hormones, inflammatory cytokines and neurotransmitters (Daskalakis, 
Bagot, Parker, Vinkers, \& de Kloet, 2013). In this context, the two-hit model of stress would suggest that developmental or lifetime stress exposure (first hit) makes an older person more vulnerable to a subsequent perceived stressor (second hit), such as social isolation, and this may reduce the resilience when faced by a COVID-19 immune challenge (Figure 3).

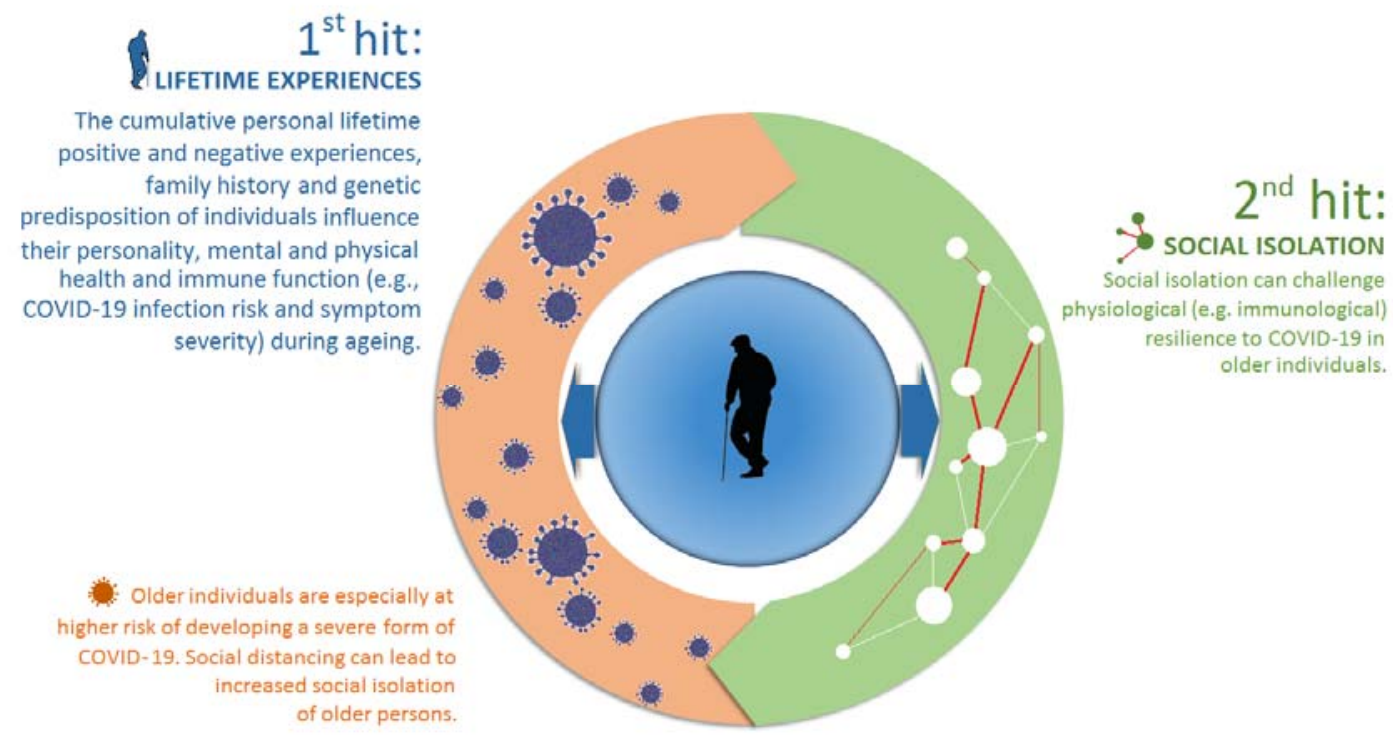

Figure 3: The two-hit model of vulnerability to COVID-19 infection in older individuals. According to the two-hit model of stress, developmental or lifetime stress exposure represent the first hit that makes an older individual more vulnerable to experiencing a second hit, such as social isolation, as being stressful. The cumulative impact of perceived stress may potentially reduce the resilience when faced by a COVID-19 immune challenge.

Thus, the cumulative impact of recurrent stresses throughout a lifetime might challenge the immunological tolerance or resilience to the COVID-19 virus, and increase the risk of morbidity and mortality due to the infection. While the first hit may induce a permanent physiological shift away from the normal homeostatic range in the attempt to adapt, the second hit may disrupt this 
fragile allostatic equilibrium and diminish resilience to disease (Maestripieri and Hoffman, 2011; McEwen, 2007). Hence, the combined impact of the two stressors is more influential than either hit alone (Faraji et al., 2017a ; Verstraeten et al., 2019b). This concept is ultimately dependent upon the individual's perception and cognitive appraisal of a challenging situation, however (Folkman et al., 1986), and social isolation may not necessarily be perceived as a stressor.

\section{MITIGATION STRATEGIES AND INTERVENTIONS}

The COVID-19 pandemic and the required social contact restriction for epidemic control have challenged daily routines of social life in the elderly population, such as restricted contact with family members, friends and even care providers for an extended period of time. Future research will provide evidence if the design and development of targeted social interventions may provide effective relief from the impact of COVID-19-related social isolation and loneliness. Previously designed social interventions for older adults showed that they can be effective when provided as one-on-one assistance (Gardiner et al., 2018). Such interventions may be implemented through information technology (IT) such as video conferencing and social media (Chiu and $\mathrm{Wu}_{2}$ 2019; Tsai et al., 2010), or solitary pet ownership and animal-assisted intervention (Gee and Mueller, 2019; Krause-Parello, 2012; Pikhartova et al., 2014). Also, a short term (2-week) smartphone-based mindfulness training for reducing emotional social isolation improved social engagement in older adults (Lindsay et al., 2019). Hence, although contradictory to the current trend that emphasizes building social networks through group settings, solitary interventions focusing on individual activities and engagements, may successfully assist individuals to combat objective and subjective isolation. Indeed, when a growing number of individuals are unable to easily participate in group-social activities, solitary context-sensitive interventions may make a meaningful, practical and cost-effective difference. Notably, the considerable diversity of the 
ageing population, in particular the sex-based variations in response to social isolation stress and lifestyle, require caregivers, social service professionals, and community authorities to consider the salience of individual differences when designing and implementing supportive interventions.

Experimental studies have also been able to specifically study the impact of social interactions on long-term health and ageing. For example, environmental enrichment (EE) by housing laboratory rodents in social groups has become a widely used paradigm that effectively reduces the chronic burden of stress and promotes long-term health and ageing (McCreary et al.., 2019). This research has also shown that females are generally more responsive to social aspects of EE than males (Faraji et al., 2018a; Faraji et al., 2018b; Faraji et al., 2017b). These benefits are associated with oxytocin-mediated telomere elongation, a biological marker of longevity, indicating improved ageing trajectories (Faraji et al., 2018a). This work has helped elucidate the biological underpinnings of social isolation and support the critical role of social enrichment as a treatment option to reverse adverse consequences of stress and enhance stress resiliency.

\section{CONCLUSION AND SYNTHESIS}

The global COVID-19 outbreak in 2020 has fundamentally changed ways of social interaction and communication at all levels and at all ages. The impact is being particularly felt in the ageing population and has called for intergenerational solidarity. Staying socially engaged is a critical part of successful ageing, and staying connected is a vital part in combating loneliness,

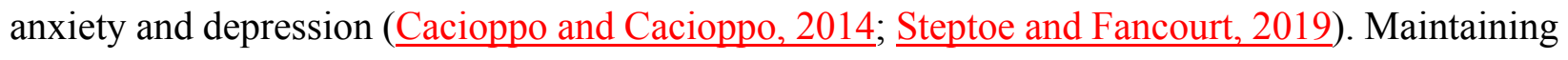
meaningful social interactions offers many benefits to elderly, including reduced risk of Alzheimer's and Parkinson's diseases (Hsiao et al., 2018; Takahashi et al., 2016), improved cognitive skills ( $\underline{\text { Hsiao et al., 2018; } \text { Stern, 2006), lower blood pressure and cardiac health (Ford et }}$ 
al., 2000; Yang et al., 2016), lower incidence of infectious diseases (Lee and Rotheram-Borus, 2001), and greater longevity (Holt-Lunstad et al., 2010). Insights into how social support enhances allostasis and resilience to stress offers insights into the underlying links between psychosocial and physical health, with important clinical relevance to predicting and preventing adverse health outcomes within a personalized medicine framework. The adverse consequences of psychosocial stress and anxiety around social isolation on physical health in the elderly should not be underestimated. The COVID-19 pandemic has markedly exposed the vulnerable situation of our society's ageing population. Here, social-physical distancing, if not implemented correctly and reasonably, may act as a double-edged sword, and impose more costs to an ageing society through increasing mortality and morbidity. This situation highlights the urgent need for further research into experience-dependent determinants of ageing trajectories and the need for development and implementation of practical and accessible interventions. At the same time, the COVID-19 pandemic also presents an unprecedented opportunity to raise public awareness of vulnerable populations and create resources for building resilience for our future and the next generations.

\section{ACKNOWLEDGEMENTS}

The authors thank Drs. Mirela Ambeskovic and Stephanie King for excellent comments on the manuscript. The authors acknowledge support by CIHR Project Scheme \#363195 (G.M.) and NSERC Discovery Grant \#5519 (G.M.).

\section{DECLARATION OF CONFLICT}

None of the authors declare any competing interests. 
REFERENCES (References included in Figures are marked by an *)

Aging-AoA-, T.A.o., 2017. A Profile of Older Americans: 2017.

Aguilera, G., 2011. HPA axis responsiveness to stress: implications for healthy aging. Experimental gerontology 46, 90-95.

Aiello, A., Farzaneh, F., Candore, G., Caruso, C., Davinelli, S., Gambino, C.M., Ligotti, M.E., Zareian, N., Accardi, G., 2019. Immunosenescence and Its Hallmarks: How to Oppose Aging Strategically? A Review of Potential Options for Therapeutic Intervention. Frontiers in immunology 10, 2247.

Alaviani, M., Khosravan, S., Alami, A., Moshki, M., 2015. The Effect of a Multi-Strategy Program on Developing Social Behaviors Based on Pender's Health Promotion Model to Prevent Loneliness of Old Women Referred to Gonabad Urban Health Centers. International journal of community based nursing and midwifery $3,132-140$.

Ambeskovic, M., Babenko, O., Ilnytskyy, Y., Kovalchuk, I., Kolb, B., Metz, G.A.S., 2019. Ancestral Stress Alters Lifetime Mental Health Trajectories and Cortical Neuromorphology via Epigenetic Regulation. Scientific reports 9, 6389 .

Ambeskovic, M., Ilnytskyy, Y., Kiss, D., Currie, C., Montina, T., Kovalchuk, I., Metz, G.A.S., 2020. Ancestral stress programs sex-specific biological aging trajectories and non-communicable disease risk. Aging 12 , 3828-3847.

Ambeskovic, M., Roseboom, T.J., Metz, G.A.S., 2017. Transgenerational effects of early environmental insults on aging and disease incidence. Neuroscience and biobehavioral reviews.

Babb, J.A., Masini, C.V., Day, H.E., Campeau, S., 2013. Sex differences in activated corticotropin-releasing factor neurons within stress-related neurocircuitry and hypothalamic-pituitary-adrenocortical axis hormones following restraint in rats. Neuroscience 234, 40-52.

Bangasser, D.A., Valentino, R.J., 2014. Sex differences in stress-related psychiatric disorders: neurobiological perspectives. Frontiers in neuroendocrinology 35, 303-319.

Banks, M.R., Willoughby, L.M., Banks, W.A., 2008. Animal-assisted therapy and loneliness in nursing homes: use of robotic versus living dogs. Journal of the American Medical Directors Association 9, 173177.

Bantry-White, E., O'Sullivan, S., Kenny, L., O'Connell, C., 2018. The symbolic representation of community in social isolation and loneliness among older people: Insights for intervention from a rural Irish case study. Health \& social care in the community 26, e552-e559.

Bassuk, S.S., Glass, T.A., Berkman, L.F., 1999. Social disengagement and incident cognitive decline in community-dwelling elderly persons. Annals of internal medicine 131, 165-173. 
Bauer, M.E., 2005. Stress, glucocorticoids and ageing of the immune system. Stress (Amsterdam, Netherlands) 8, 69-83.

Beckie, T.M., 2012. A systematic review of allostatic load, health, and health disparities. Biological research for nursing 14, 311-346.

Beery, A.K., Kaufer, D., 2015. Stress, social behavior, and resilience: insights from rodents. Neurobiology of stress 1, 116-127.

Bellavance, M.A., Rivest, S., 2014. The HPA - Immune Axis and the Immunomodulatory Actions of Glucocorticoids in the Brain. Frontiers in immunology 5, 136.

*Beller, J., Wagner, A., 2018. Loneliness, social isolation, their synergistic interaction, and mortality. Health psychology : official journal of the Division of Health Psychology, American Psychological Association 37, 808-813.

Belvederi Murri, M., Pariante, C., Mondelli, V., Masotti, M., Atti, A.R., Mellacqua, Z., Antonioli, M., Ghio, L., Menchetti, M., Zanetidou, S., Innamorati, M., Amore, M., 2014. HPA axis and aging in depression: systematic review and meta-analysis. Psychoneuroendocrinology 41, 46-62.

Berger, M., Taylor, S., Harriss, L., Campbell, S., Thompson, F., Jones, S., Sushames, A., Amminger, G.P., Sarnyai, Z., McDermott, R., 2019. Hair cortisol, allostatic load, and depressive symptoms in Australian Aboriginal and Torres Strait Islander people. Stress (Amsterdam, Netherlands) 22, 312-320.

Böbel, T.S., Hackl, S.B., Langgartner, D., Jarczok, M.N., Rohleder, N., Rook, G.A., Lowry, C.A., Gündel, H., Waller, C., Reber, S.O., 2018. Less immune activation following social stress in rural vs. urban participants raised with regular or no animal contact, respectively. Proceedings of the National Academy of Sciences of the United States of America 115, 5259-5264.

Boen, C.E., Barrow, D.A., Bensen, J.T., Farnan, L., Gerstel, A., Hendrix, L.H., Yang, Y.C., 2018. Social Relationships, Inflammation, and Cancer Survival. Cancer epidemiology, biomarkers \& prevention : a publication of the American Association for Cancer Research, cosponsored by the American Society of Preventive Oncology 27, 541-549.

Boen, H., Dalgard, O.S., Bjertness, E., 2012. The importance of social support in the associations between psychological distress and somatic health problems and socio-economic factors among older adults living at home: a cross sectional study. BMC geriatrics 12, 27.

Bos, P.A., Terburg, D., van Honk, J., 2010. Testosterone decreases trust in socially naive humans. Proceedings of the National Academy of Sciences of the United States of America 107, 9991-9995.

Boyle, P.A., Barnes, L.L., Buchman, A.S., Bennett, D.A., 2009. Purpose in life is associated with mortality among community-dwelling older persons. Psychosomatic medicine 71, 574-579.

Brooks, S.K., Webster, R.K., Smith, L.E., Woodland, L., Wessely, S., Greenberg, N., Rubin, G.J., 2020. The psychological impact of quarantine and how to reduce it: rapid review of the evidence. Lancet (London, England) 395, 912-920. 
*Brown, C.C., Raio, C.M., Neta, M., 2017. Cortisol responses enhance negative valence perception for ambiguous facial expressions. Scientific reports 7, 15107.

Bruggencate TT, L.K., Sturm J., 2018. Social needs of older people: a systematic literature review. Ageing and Society $38,1745-1770$.

Burford, N.G., Webster, N.A., Cruz-Topete, D., 2017. Hypothalamic-Pituitary-Adrenal Axis Modulation of Glucocorticoids in the Cardiovascular System. International journal of molecular sciences 18.

*Cacioppo, J.T., Cacioppo, S., 2014. Older adults reporting social isolation or loneliness show poorer cognitive function 4 years later. Evidence-based nursing 17, 59-60.

Cacioppo, J.T., Cacioppo, S., 2018. The growing problem of loneliness. Lancet (London, England) 391, 426.

Cacioppo, J.T., Hawkley, L.C., Norman, G.J., Berntson, G.G., 2011. Social isolation. Annals of the New York Academy of Sciences 1231, 17-22.

Cacioppo, S., Grippo, A.J., London, S., Goossens, L., Cacioppo, J.T., 2015. Loneliness: clinical import and interventions. Perspectives on psychological science : a journal of the Association for Psychological Science 10, 238-249.

Caldwell, H.K., 2018. Oxytocin and sex differences in behavior. Current Opinion in Behavioral Sciences 23, 13-20.

Canet, G., Hernandez, C., Zussy, C., Chevallier, N., Desrumaux, C., Givalois, L., 2019. Is AD a StressRelated Disorder? Focus on the HPA Axis and Its Promising Therapeutic Targets. Frontiers in aging neuroscience 11, 269.

Chau, T.T., Wang, K.Y., 2020. An association between air pollution and daily most frequently visits of eighteen outpatient diseases in an industrial city. Scientific reports 10, 2321.

Cherif, H., Tarry, J.L., Ozanne, S.E., Hales, C.N., 2003. Ageing and telomeres: a study into organ- and gender-specific telomere shortening. Nucleic acids research 31, 1576-1583.

Chiu, C.J., Wu, C.H., 2019. Information and Communications Technology as a Health Promotion Method for Older Adults in Assisted-Living Facilities: Three-Arm Group-Randomized Trial. JMIR aging 2, e12633.

Chmielewski, P., Borysławski, K., Strzelec, B., 2016. Contemporary views on human aging and longevit. Anthropological Review 79, 115-142.

*Choleris, E., Clipperton-Allen, A.E., Phan, A., Valsecchi, P., Kavaliers, M., 2012. Estrogenic involvement in social learning, social recognition and pathogen avoidance. Frontiers in neuroendocrinology 33, 140159.

Choleris, E., Galea, L.A.M., Sohrabji, F., Frick, K.M., 2018. Sex differences in the brain: Implications for behavioral and biomedical research. Neuroscience and biobehavioral reviews 85, 126-145. 
Choleris, E., Gustafsson, J.A., Korach, K.S., Muglia, L.J., Pfaff, D.W., Ogawa, S., 2003. An estrogendependent four-gene micronet regulating social recognition: a study with oxytocin and estrogen receptor-alpha and -beta knockout mice. Proceedings of the National Academy of Sciences of the United States of America 100, 6192-6197.

Cohen, S., 2004. Social relationships and health. The American psychologist 59, 676-684.

*Cole, S.W., Capitanio, J.P., Chun, K., Arevalo, J.M., Ma, J., Cacioppo, J.T., 2015. Myeloid differentiation architecture of leukocyte transcriptome dynamics in perceived social isolation. Proceedings of the National Academy of Sciences of the United States of America 112, 15142-15147.

Cornwell, E.Y., Waite, L.J., 2009. Social disconnectedness, perceived isolation, and health among older adults. Journal of health and social behavior 50, 31-48.

Coyle, C.E., Dugan, E., 2012. Social isolation, loneliness and health among older adults. Journal of aging and health 24, 1346-1363.

Csernansky, J.G., Dong, H., Fagan, A.M., Wang, L., Xiong, C., Holtzman, D.M., Morris, J.C., 2006. Plasma cortisol and progression of dementia in subjects with Alzheimer-type dementia. The American journal of psychiatry 163, 2164-2169.

Danese, A., McEwen, B.S., 2012. Adverse childhood experiences, allostasis, allostatic load, and agerelated disease. Physiology \& behavior 106, 29-39.

Daskalakis, N.P., Bagot, R.C., Parker, K.J., Vinkers, C.H., de Kloet, E.R., 2013. The three-hit concept of vulnerability and resilience: toward understanding adaptation to early-life adversity outcome.

Psychoneuroendocrinology 38, 1858-1873.

de Almeida Roediger, M., de Fátima Nunes Marucci, M., Duim, E.L., Santos, J.L.F., de Oliveira Duarte, Y.A., de Oliveira, C., 2019. Inflammation and quality of life in later life: findings from the health, wellbeing and aging study (SABE). Health and quality of life outcomes 17, 26.

Del Giudice, M., Gangestad, S.W., 2018. Rethinking IL-6 and CRP: Why they are more than inflammatory biomarkers, and why it matters. Brain, behavior, and immunity 70, 61-75.

DESA, U.N., 2017. World Population Ageing 2017 - Highlights.

DeVries, A.C., Glasper, E.R., Detillion, C.E., 2003. Social modulation of stress responses. Physiology \& behavior 79, 399-407.

Diamanti-Kandarakis, E., Dattilo, M., Macut, D., Duntas, L., Gonos, E.S., Goulis, D.G., Gantenbein, C.K., Kapetanou, M., Koukkou, E., Lambrinoudaki, I., Michalaki, M., Eftekhari-Nader, S., Pasquali, R., Peppa, M., Tzanela, M., Vassilatou, E., Vryonidou, A., 2017. MECHANISMS IN ENDOCRINOLOGY: Aging and antiaging: a Combo-Endocrinology overview. European journal of endocrinology 176, R283-r308.

Dickerson, S.S., Kemeny, M.E., 2004. Acute stressors and cortisol responses: a theoretical integration and synthesis of laboratory research. Psychological bulletin 130, 355-391. 
Dowd, J.B., Andriano, L., Brazel, D.M., Rotondi, V., Block, P., Ding, X., Liu, Y., Mills, M.C., 2020.

Demographic science aids in understanding the spread and fatality rates of COVID-19. Proceedings of the National Academy of Sciences of the United States of America 117, 9696-9698.

Edwards, C.J., Williams, E., 2010. The role of interleukin-6 in rheumatoid arthritis-associated osteoporosis. Osteoporosis international : a journal established as result of cooperation between the European Foundation for Osteoporosis and the National Osteoporosis Foundation of the USA 21, 12871293.

Edwards, K.A., Alschuler, K.A., Ehde, D.M., Battalio, S.L., Jensen, M.P., 2017. Changes in Resilience Predict Function in Adults With Physical Disabilities: A Longitudinal Study. Archives of physical medicine and rehabilitation 98, 329-336.

Elaine Cumming, L.R.D., David S. Newell, Isabel McCaffrey, 1960. Disengagement-A Tentative Theory of Aging. Sociometry 23, 23.

*Elliot, A.J., Heffner, K.L., Mooney, C.J., Moynihan, J.A., Chapman, B.P., 2018. Social Relationships and Inflammatory Markers in the MIDUS Cohort: The Role of Age and Gender Differences. Journal of aging and health 30, 904-923.

Elmer, E.M., 2018. Social isolation and loneliness among seniors in Vancouver:Strategies for reduction and prevention. A report to the City of Vancouver and Vancouver Coastal Health.

Elovainio, M., Hakulinen, C., Pulkki-Råback, L., Virtanen, M., Josefsson, K., Jokela, M., Vahtera, J., Kivimäki, M., 2017. Contribution of risk factors to excess mortality in isolated and lonely individuals: an analysis of data from the UK Biobank cohort study. The Lancet. Public health 2, e260-e266.

Eng, P.M., Rimm, E.B., Fitzmaurice, G., Kawachi, I., 2002. Social ties and change in social ties in relation to subsequent total and cause-specific mortality and coronary heart disease incidence in men. American journal of epidemiology 155, 700-709.

Ennis, G.E., An, Y., Resnick, S.M., Ferrucci, L., O'Brien, R.J., Moffat, S.D., 2017. Long-term cortisol measures predict Alzheimer disease risk. Neurology 88, 371-378.

Evertz, K., Janus, L., Linder, R., 2020. Handbook of Prenatal and Perinatal Psychology: Integrating Research and Practice.

Fakoya, O.A., McCorry, N.K., Donnelly, M., 2020. Loneliness and social isolation interventions for older adults: a scoping review of reviews. BMC public health 20, 129.

*Faraji, J., Karimi, M., Soltanpour, N., Moharrerie, A., Rouhzadeh, Z., Lotfi, H., Hosseini, S.A., Jafari, S.Y., Roudaki, S., Moeeini, R., Metz, G.A., 2018a. Oxytocin-mediated social enrichment promotes longer telomeres and novelty seeking. eLife 7.

*Faraji, J., Karimi, M., Soltanpour, N., Rouhzadeh, Z., Roudaki, S., Hosseini, S.A., Jafari, S.Y., Abdollahi, A.A., Soltanpour, N., Moeeini, R., Metz, G.A.S., 2018b. Intergenerational Sex-Specific Transmission of Maternal Social Experience. Scientific reports 8, 10529. 
Faraji, J., Metz, G.A.S., 2020. Infrared Thermography Reveals Sex-Specific Responses to Stress in Mice. Front. Behav. Neurosci.

Faraji, J., Soltanpour, N., Ambeskovic, M., Zucchi, F.C.R., Beaumier, P., Kovalchuk, I., Metz, G.A.S., 2017a. Evidence for Ancestral Programming of Resilience in a Two-Hit Stress Model. Frontiers in behavioral neuroscience $11,89$.

Faraji, J., Soltanpour, N., Lotfi, H., Moeeini, R., Moharreri, A.R., Roudaki, S., Hosseini, S.A., Olson, D.M., Abdollahi, A.A., Soltanpour, N., Mohajerani, M.H., Metz, G.A.S., 2017b. Lack of Social Support Raises Stress Vulnerability in Rats with a History of Ancestral Stress. Scientific reports 7, 5277.

Ferrari, E., Cravello, L., Muzzoni, B., Casarotti, D., Paltro, M., Solerte, S.B., Fioravanti, M., Cuzzoni, G., Pontiggia, B., Magri, F., 2001. Age-related changes of the hypothalamic-pituitary-adrenal axis: pathophysiological correlates. European journal of endocrinology 144, 319-329.

Ferrucci, L., Harris, T.B., Guralnik, J.M., Tracy, R.P., Corti, M.C., Cohen, H.J., Penninx, B., Pahor, M., Wallace, R., Havlik, R.J., 1999. Serum IL-6 level and the development of disability in older persons. Journal of the American Geriatrics Society 47, 639-646.

Flaxman, S., Mishra, S., Gandy, A., Unwin, H.J.T., Mellan, T.A., Coupland, H., Whittaker, C., Zhu, H., Berah, T., Eaton, J.W., Monod, M., Ghani, A.C., Donnelly, C.A., Riley, S.M., Vollmer, M.A.C., Ferguson, N.M., Okell, L.C., Bhatt, S., 2020. Estimating the effects of non-pharmaceutical interventions on COVID19 in Europe. Nature.

Ford, E.S., Ahluwalia, I.B., Galuska, D.A., 2000. Social relationships and cardiovascular disease risk factors: findings from the third national health and nutrition examination survey. Preventive medicine 30, 83-92.

Franceschi, C., Bonafè, M., Valensin, S., Olivieri, F., De Luca, M., Ottaviani, E., De Benedictis, G., 2000. Inflamm-aging. An evolutionary perspective on immunosenescence. Annals of the New York Academy of Sciences 908, 244-254.

Friedman, E.M., Hayney, M.S., Love, G.D., Urry, H.L., Rosenkranz, M.A., Davidson, R.J., Singer, B.H., Ryff, C.D., 2005. Social relationships, sleep quality, and interleukin- 6 in aging women. Proceedings of the National Academy of Sciences of the United States of America 102, 18757-18762.

Fulop, T., Larbi, A., Dupuis, G., Le Page, A., Frost, E.H., Cohen, A.A., Witkowski, J.M., Franceschi, C., 2017. Immunosenescence and Inflamm-Aging As Two Sides of the Same Coin: Friends or Foes? Frontiers in immunology 8, 1960.

*Gabor, C.S., Phan, A., Clipperton-Allen, A.E., Kavaliers, M., Choleris, E., 2012. Interplay of oxytocin, vasopressin, and sex hormones in the regulation of social recognition. Behavioral neuroscience 126, 97109.

Gaffey, A.E., Bergeman, C.S., Clark, L.A., Wirth, M.M., 2016. Aging and the HPA axis: Stress and resilience in older adults. Neuroscience and biobehavioral reviews 68, 928-945. 
Gardiner, C., Geldenhuys, G., Gott, M., 2018. Interventions to reduce social isolation and loneliness among older people: an integrative review. Health \& social care in the community $26,147-157$.

*Gardner, M., Lightman, S., Kuh, D., Comijs, H., Deeg, D., Gallacher, J., Geoffroy, M.C., Kivimaki, M., Kumari, M., Power, C., Hardy, R., Richards, M., Ben-Shlomo, Y., 2019. Dysregulation of the hypothalamic pituitary adrenal (HPA) axis and cognitive capability at older ages: individual participant meta-analysis of five cohorts. Scientific reports 9, 4555.

Gatto, M., Bertuzzo, E., Mari, L., Miccoli, S., Carraro, L., Casagrandi, R., Rinaldo, A., 2020. Spread and dynamics of the COVID-19 epidemic in Italy: Effects of emergency containment measures. Proceedings of the National Academy of Sciences of the United States of America 117, 10484-10491.

Ge, L., Yap, C.W., Ong, R., Heng, B.H., 2017. Social isolation, loneliness and their relationships with depressive symptoms: A population-based study. PloS one 12, e0182145.

Gee, N.R., Mueller, M.K., 2019. A Systematic Review of Research on Pet Ownership and Animal Interactions among Older Adults. Anthrozoös 32, 183-207.

Giefing-Kröll, C., Berger, P., Lepperdinger, G., Grubeck-Loebenstein, B., 2015. How sex and age affect immune responses, susceptibility to infections, and response to vaccination. Aging cell 14, 309-321.

Giordano, R., Bo, M., Pellegrino, M., Vezzari, M., Baldi, M., Picu, A., Balbo, M., Bonelli, L., Migliaretti, G., Ghigo, E., Arvat, E., 2005. Hypothalamus-pituitary-adrenal hyperactivity in human aging is partially refractory to stimulation by mineralocorticoid receptor blockade. The Journal of clinical endocrinology and metabolism 90, 5656-5662.

Glei, D.A., Goldman, N., Ryff, C.D., Lin, Y.H., Weinstein, M., 2012. Social relationships and inflammatory markers: an analysis of Taiwan and the U.S. Social science \& medicine (1982) 74, 1891-1899.

Goel, N., Workman, J.L., Lee, T.T., Innala, L., Viau, V., 2014. Sex differences in the HPA axis. Comprehensive Physiology 4, 1121-1155.

Goncharova, N., Chigarova, O., Rudenko, N., Oganyan, T., 2019. Glucocorticoid Negative Feedback in Regulation of the Hypothalamic-Pituitary-Adrenal Axis in Rhesus Monkeys With Various Types of Adaptive Behavior: Individual and Age-Related Differences. Frontiers in endocrinology 10, 24.

Goncharova, N.D., 2014. [Age-related changes of the hypothalamic-pituitary-adrenal axis: experimental studies in primates]. Advances in gerontology = Uspekhi gerontologii 27, 269-274.

Grant, N., Hamer, M., Steptoe, A., 2009. Social isolation and stress-related cardiovascular, lipid, and cortisol responses. Annals of behavioral medicine : a publication of the Society of Behavioral Medicine 37, 29-37.

*Grewen, K.M., Light, K.C., 2011. Plasma oxytocin is related to lower cardiovascular and sympathetic reactivity to stress. Biological psychology $87,340-349$. 
*Gronewold, J., Kropp, R., Lehmann, N., Schmidt, B., Weyers, S., Siegrist, J., Dragano, N., Jockel, K.H., Erbel, R., Hermann, D.M., 2020. Association of social relationships with incident cardiovascular events and all-cause mortality. Heart (British Cardiac Society).

Gronning, K., Espnes, G.A., Nguyen, C., Rodrigues, A.M.F., Gregorio, M.J., Sousa, R., Canhao, H., Andre, B., 2018. Psychological distress in elderly people is associated with diet, wellbeing, health status, social support and physical functioning- a HUNT3 study. BMC geriatrics 18, 205.

Guan, W.J., Ni, Z.Y., Hu, Y., Liang, W.H., Ou, C.Q., He, J.X., Liu, L., Shan, H., Lei, C.L., Hui, D.S.C., Du, B., Li, L.J., Zeng, G., Yuen, K.Y., Chen, R.C., Tang, C.L., Wang, T., Chen, P.Y., Xiang, J., Li, S.Y., Wang, J.L., Liang, Z.J., Peng, Y.X., Wei, L., Liu, Y., Hu, Y.H., Peng, P., Wang, J.M., Liu, J.Y., Chen, Z., Li, G., Zheng, Z.J., Qiu, S.Q., Luo, J., Ye, C.J., Zhu, S.Y., Zhong, N.S., 2020. Clinical Characteristics of Coronavirus Disease 2019 in China. The New England journal of medicine 382, 1708-1720.

Guerra-Silveira, F., Abad-Franch, F., 2013. Sex bias in infectious disease epidemiology: patterns and processes. PloS one 8, e62390.

*Gunnar, M.R., 2017. Social Buffering of Stress in Development: A Career Perspective. Perspectives on psychological science : a journal of the Association for Psychological Science 12, 355-373.

Gust, D.A., Wilson, M.E., Stocker, T., Conrad, S., Plotsky, P.M., Gordon, T.P., 2000. Activity of the hypothalamic-pituitary-adrenal axis is altered by aging and exposure to social stress in female rhesus monkeys. The Journal of clinical endocrinology and metabolism 85, 2556-2563.

Hajek, A., König, H.H., 2019. Obesity and loneliness. Findings from a longitudinal population-based study in the second half of life in Germany. Psychogeriatrics : the official journal of the Japanese Psychogeriatric Society 19, 135-140.

Hamlin, J.K., Wynn, K., Bloom, P., 2007. Social evaluation by preverbal infants. Nature 450, 557-559. Handa, R.J., McGivern, R.F., 2010. Stress response: sex differences. . Encycl. Neurosci. , 511-517.

Hari, R., Henriksson, L., Malinen, S., Parkkonen, L., 2015. Centrality of Social Interaction in Human Brain Function. Neuron 88, 181-193.

Harris, T.B., Ferrucci, L., Tracy, R.P., Corti, M.C., Wacholder, S., Ettinger, W.H., Jr., Heimovitz, H., Cohen, H.J., Wallace, R., 1999. Associations of elevated interleukin-6 and C-reactive protein levels with mortality in the elderly. The American journal of medicine 106, 506-512.

*Hawkley, L.C., Cacioppo, J.T., 2010. Loneliness matters: a theoretical and empirical review of consequences and mechanisms. Annals of behavioral medicine : a publication of the Society of Behavioral Medicine 40, 218-227.

*Heck, A.L., Handa, R.J., 2019. Sex differences in the hypothalamic-pituitary-adrenal axis' response to stress: an important role for gonadal hormones. Neuropsychopharmacology : official publication of the American College of Neuropsychopharmacology 44, 45-58.

Heffner, K.L., 2011. Neuroendocrine effects of stress on immunity in the elderly: implications for inflammatory disease. Immunology and allergy clinics of North America 31, 95-108. 
Heffner, K.L., Waring, M.E., Roberts, M.B., Eaton, C.B., Gramling, R., 2011. Social isolation, C-reactive protein, and coronary heart disease mortality among community-dwelling adults. Social science \& medicine (1982) 72, 1482-1488.

Heinrich, L.M., Gullone, E., 2006. The clinical significance of loneliness: a literature review. Clinical psychology review 26, 695-718.

*Heinrichs, M., Baumgartner, T., Kirschbaum, C., Ehlert, U., 2003. Social support and oxytocin interact to suppress cortisol and subjective responses to psychosocial stress. Biological psychiatry 54, 1389-1398. Hellwig, S., Domschke, K., 2019. Anxiety in Late Life: An Update on Pathomechanisms. Gerontology 65, 465-473.

Heo, J., Chun, S., Lee, S., Lee, K.H., Kim, J., 2015. Internet use and well-being in older adults. Cyberpsychology, behavior and social networking 18, 268-272.

Herman, J.P., McKlveen, J.M., Ghosal, S., Kopp, B., Wulsin, A., Makinson, R., Scheimann, J., Myers, B., 2016. Regulation of the Hypothalamic-Pituitary-Adrenocortical Stress Response. Comprehensive Physiology 6, 603-621.

*Holt-Lunstad, J., Birmingham, W.C., Light, K.C., 2015. Relationship quality and oxytocin: Influence of stable and modifiable aspects of relationships. Journal of Social and Personal Relationships 32, 472-490.

*Holt-Lunstad, J., Smith, T.B., Layton, J.B., 2010. Social relationships and mortality risk: a meta-analytic review. PLoS medicine 7, e1000316.

Holwerda, T.J., Beekman, A.T., Deeg, D.J., Stek, M.L., van Tilburg, T.G., Visser, P.J., Schmand, B., Jonker, C., Schoevers, R.A., 2012. Increased risk of mortality associated with social isolation in older men: only when feeling lonely? Results from the Amsterdam Study of the Elderly (AMSTEL). Psychological medicine $42,843-853$.

Hostinar, C.E., Gunnar, M.R., 2013. Future directions in the study of social relationships as regulators of the HPA axis across development. Journal of clinical child and adolescent psychology : the official journal for the Society of Clinical Child and Adolescent Psychology, American Psychological Association, Division $5342,564-575$.

*Hostinar, C.E., Sullivan, R.M., Gunnar, M.R., 2014. Psychobiological mechanisms underlying the social buffering of the hypothalamic-pituitary-adrenocortical axis: a review of animal models and human studies across development. Psychological bulletin 140, 256-282.

*House, J.S., Landis, K.R., Umberson, D., 1988. Social relationships and health. Science (New York, N.Y.) 241, 540-545.

Hoyt, J.R., Langwig, K.E., Sun, K., Parise, K.L., Li, A., Wang, Y., Huang, X., Worledge, L., Miller, H., White, J.P., Kaarakka, H.M., Redell, J.A., Görföl, T., Boldogh, S.A., Fukui, D., Sakuyama, M., Yachimori, S., Sato, A., Dalannast, M., Jargalsaikhan, A., Batbayar, N., Yovel, Y., Amichai, E., Natradze, I., Frick, W.F., Foster, J.T., Feng, J., Kilpatrick, A.M., 2020. Environmental reservoir dynamics predict global infection patterns and population impacts for the fungal disease white-nose syndrome. Proceedings of the National Academy of Sciences of the United States of America 117, 7255-7262. 
Hsiang, S., Allen, D., Annan-Phan, S., Bell, K., Bolliger, I., Chong, T., Druckenmiller, H., Huang, L.Y., Hultgren, A., Krasovich, E., Lau, P., Lee, J., Rolf, E., Tseng, J., Wu, T., 2020. The effect of large-scale anticontagion policies on the COVID-19 pandemic. Nature.

Hsiao, Y.H., Chang, C.H., Gean, P.W., 2018. Impact of social relationships on Alzheimer's memory impairment: mechanistic studies. Journal of biomedical science 25,3 .

*Iob, E., Kirschbaum, C., Steptoe, A., 2018. Positive and negative social support and HPA-axis hyperactivity: Evidence from glucocorticoids in human hair. Psychoneuroendocrinology 96, 100-108.

Iob, E., Kirschbaum, C., Steptoe, A., 2019. Persistent depressive symptoms, HPA-axis hyperactivity, and inflammation: the role of cognitive-affective and somatic symptoms. Molecular psychiatry.

lob, E., Kirschbaum, C., Steptoe, A., 2020. Persistent depressive symptoms, HPA-axis hyperactivity, and inflammation: the role of cognitive-affective and somatic symptoms. Molecular psychiatry 25, $1130-$ 1140.

Isik, L., Koldewyn, K., Beeler, D., Kanwisher, N., 2017. Perceiving social interactions in the posterior superior temporal sulcus. Proceedings of the National Academy of Sciences of the United States of America 114, E9145-e9152.

Jiang, N., He, J., Weinstein, J.A., Penland, L., Sasaki, S., He, X.S., Dekker, C.L., Zheng, N.Y., Huang, M., Sullivan, M., Wilson, P.C., Greenberg, H.B., Davis, M.M., Fisher, D.S., Quake, S.R., 2013. Lineage structure of the human antibody repertoire in response to influenza vaccination. Science translational medicine 5 , 171 ra119.

Juster, R.P., McEwen, B.S., Lupien, S.J., 2010. Allostatic load biomarkers of chronic stress and impact on health and cognition. Neuroscience and biobehavioral reviews 35, 2-16.

Karlsson, S., Henningsson, S., Hovey, D., Zettergren, A., Jonsson, L., Cortes, D.S., Melke, J., Laukka, P., Fischer, H., Westberg, L., 2016. Social memory associated with estrogen receptor polymorphisms in women. Social cognitive and affective neuroscience 11, 877-883.

Kelman, H.C., 1958. Compliance, Identification, and Internalization: Three Processes of Attitude Change. Journal of Conflict Resolution 2, 51-60.

*Kiecolt-Glaser, J.K., Gouin, J.P., Hantsoo, L., 2010. Close relationships, inflammation, and health. Neuroscience and biobehavioral reviews 35, 33-38.

Kiecolt-Glaser, J.K., Preacher, K.J., MacCallum, R.C., Atkinson, C., Malarkey, W.B., Glaser, R., 2003. Chronic stress and age-related increases in the proinflammatory cytokine IL-6. Proceedings of the National Academy of Sciences of the United States of America 100, 9090-9095.

Kikusui, T., 2018. How does social enrichment produce health benefits? eLife 7. 
Kobrosly, R.W., van Wijngaarden, E., Seplaki, C.L., Cory-Slechta, D.A., Moynihan, J., 2014. Depressive symptoms are associated with allostatic load among community-dwelling older adults. Physiology \& behavior 123, 223-230.

Koelman, L., Pivovarova-Ramich, O., Pfeiffer, A.F.H., Grune, T., Aleksandrova, K., 2019. Cytokines for evaluation of chronic inflammatory status in ageing research: reliability and phenotypic characterisation. Immunity \& ageing : I \& A 16, 11.

Kokras, N., Hodes, G.E., Bangasser, D.A., Dalla, C., 2019. Sex differences in the hypothalamic-pituitaryadrenal axis: An obstacle to antidepressant drug development? British journal of pharmacology 176, 4090-4106.

Krabbe, K.S., Pedersen, M., Bruunsgaard, H., 2004. Inflammatory mediators in the elderly. Experimental gerontology 39, 687-699.

Krause-Parello, C.A., 2012. Pet ownership and older women: the relationships among loneliness, pet attachment support, human social support, and depressed mood. Geriatric nursing (New York, N.Y.) 33, 194-203.

Krause, N., Rook, K.S., 2003. Negative interaction in late life: issues in the stability and generalizability of conflict across relationships. The journals of gerontology. Series B, Psychological sciences and social sciences 58, P88-99.

*Kreuder, A.K., Scheele, D., Schultz, J., Hennig, J., Marsh, N., Dellert, T., Ettinger, U., Philipsen, A., Babasiz, M., Herscheid, A., Remmersmann, L., Stirnberg, R., Stöcker, T., Hurlemann, R., 2020. Common and dissociable effects of oxytocin and lorazepam on the neurocircuitry of fear. Proceedings of the National Academy of Sciences of the United States of America 117, 11781-11787.

*Lai, J.C., Chong, A.M., Siu, O.T., Evans, P., Chan, C.L., Ho, R.T., 2012. Social network characteristics and salivary cortisol in healthy older people. TheScientificWorldJournal 2012, 929067.

Lavretsky, H., Newhouse, P.A., 2012. Stress, inflammation, and aging. The American journal of geriatric psychiatry : official journal of the American Association for Geriatric Psychiatry 20, 729-733.

Lee, J.K., Bettencourt, R., Brenner, D., Le, T.A., Barrett-Connor, E., Loomba, R., 2012. Association between serum interleukin- 6 concentrations and mortality in older adults: the Rancho Bernardo study. PloS one 7, e34218.

Lee, M., Rotheram-Borus, M.J., 2001. Challenges associated with increased survival among parents living with HIV. American journal of public health 91, 1303-1309.

*Lerner R.M., E.M.A., Mistry J., \& Weiner I.B., 2013. Handbook of Psychology: Developmental Psychology. John Wiley \& Sons Inc.

Lincoln, K.D., 2000. Social Support, Negative Social Interactions, and Psychological Well-Being. The Social service review 74, 231-252. 
Lindsay, E.K., Young, S., Brown, K.W., Smyth, J.M., Creswell, J.D., 2019. Mindfulness training reduces loneliness and increases social contact in a randomized controlled trial. Proceedings of the National Academy of Sciences of the United States of America 116, 3488-3493.

Lindsay Smith, G., Banting, L., Eime, R., O'Sullivan, G., van Uffelen, J.G.Z., 2017. The association between social support and physical activity in older adults: a systematic review. The international journal of behavioral nutrition and physical activity 14, 56 .

Lippitz, B.E., Harris, R.A., 2016. Cytokine patterns in cancer patients: A review of the correlation between interleukin 6 and prognosis. Oncoimmunology 5, e1093722.

Lombardo, M.V., Auyeung, B., Pramparo, T., Quartier, A., Courraud, J., Holt, R.J., Waldman, J., Ruigrok, A.N.V., Mooney, N., Bethlehem, R.A.I., Lai, M.C., Kundu, P., Bullmore, E.T., Mandel, J.L., Piton, A., BaronCohen, S., 2018. Sex-specific impact of prenatal androgens on social brain default mode subsystems. Molecular psychiatry.

Lopez-Otin, C., Blasco, M.A., Partridge, L., Serrano, M., Kroemer, G., 2013. The hallmarks of aging. Cell 153, 1194-1217.

Loucks, E.B., Berkman, L.F., Gruenewald, T.L., Seeman, T.E., 2006a. Relation of social integration to inflammatory marker concentrations in men and women 70 to 79 years. The American journal of cardiology 97, 1010-1016.

Loucks, E.B., Sullivan, L.M., D'Agostino, R.B., Sr., Larson, M.G., Berkman, L.F., Benjamin, E.J., $2006 \mathrm{~b}$. Social networks and inflammatory markers in the Framingham Heart Study. Journal of biosocial science $38,835-842$.

Lunyera, J., Stanifer, J.W., Davenport, C.A., Mohottige, D., Bhavsar, N.A., Scialla, J.J., Pendergast, J., Boulware, L.E., Diamantidis, C.J., 2020. Life Course Socioeconomic Status, Allostatic Load, and Kidney Health in Black Americans. Clinical journal of the American Society of Nephrology : CJASN 15, 341-348. M., D.I.F., 2018. Oxidation and Inflammation in the Immune and Nervous Systems, a Link Between Aging and Anxiety, in: Fulop T., F.C., Hirokawa K., Pawelec G. (Ed.), Handbook of Immunosenescence. Springer,, Cham.

*Ma, Y., Li, S., Wang, C., Liu, Y., Li, W., Yan, X., Chen, Q., Han, S., 2016. Distinct oxytocin effects on belief updating in response to desirable and undesirable feedback. Proceedings of the National Academy of Sciences of the United States of America 113, 9256-9261.

MacLusky, N.J., Yuan, H., Elliott, J., Brown, T.J., 1996. Sex differences in corticosteroid binding in the rat brain: an in vitro autoradiographic study. Brain research 708, 71-81.

*Maestripieri, D., Hoffman, C.L., 2011. Chronic stress, allostatic load, and aging in nonhuman primates. Development and psychopathology 23, 1187-1195.

Maggio, M., Guralnik, J.M., Longo, D.L., Ferrucci, L., 2006. Interleukin-6 in aging and chronic disease: a magnificent pathway. The journals of gerontology. Series A, Biological sciences and medical sciences 61 , 575-584. 
Malcolm, M., Frost, H., Cowie, J., 2019. Loneliness and social isolation causal association with healthrelated lifestyle risk in older adults: a systematic review and meta-analysis protocol. Systematic reviews $8,48$.

Manini, T., 2011. Development of physical disability in older adults. Current aging science 4, 184-191. Mantella, R.C., Butters, M.A., Amico, J.A., Mazumdar, S., Rollman, B.L., Begley, A.E., Reynolds, C.F., Lenze, E.J., 2008. Salivary cortisol is associated with diagnosis and severity of late-life generalized anxiety disorder. Psychoneuroendocrinology 33, 773-781.

*Márquez, E.J., Chung, C.H., Marches, R., Rossi, R.J., Nehar-Belaid, D., Eroglu, A., Mellert, D.J., Kuchel, G.A., Banchereau, J., Ucar, D., 2020. Sexual-dimorphism in human immune system aging. Nature communications $11,751$.

Matt, G.E., Dean, A., 1993. Social support from friends and psychological distress among elderly persons: moderator effects of age. Journal of health and social behavior 34, 187-200.

Mattei, J., Demissie, S., Falcon, L.M., Ordovas, J.M., Tucker, K., 2010. Allostatic load is associated with chronic conditions in the Boston Puerto Rican Health Study. Social science \& medicine (1982) 70, 19881996.

McAuley, M.T., Kenny, R.A., Kirkwood, T.B., Wilkinson, D.J., Jones, J.J., Miller, V.M., 2009. A mathematical model of aging-related and cortisol induced hippocampal dysfunction. BMC neuroscience $10,26$.

McClintock, M.K., Dale, W., Laumann, E.O., Waite, L., 2016. Empirical redefinition of comprehensive health and well-being in the older adults of the United States. Proceedings of the National Academy of Sciences of the United States of America 113, E3071-3080.

McCreary, J.K., Erickson, Z.T., Hao, Y., Ilnytskyy, Y., Kovalchuk, I., Metz, G.A., 2016. Environmental Intervention as a Therapy for Adverse Programming by Ancestral Stress. Scientific reports 6, 37814.

McCreary, J.K., Erickson, Z.T., Paxman, E., Kiss, D., Montina, T., Olson, D.M., Metz, G.A.S., 2019. The rat cumulative allostatic load measure (rCALM): a new translational assessment of the burden of stress. Environmental epigenetics 5, dvz005.

*McEwen, B.S., 2002. Sex, stress and the hippocampus: allostasis, allostatic load and the aging process. Neurobiology of aging 23, 921-939.

McEwen, B.S., 2007. Physiology and neurobiology of stress and adaptation: central role of the brain. Physiological reviews 87, 873-904.

McEwen, B.S., Sapolsky, R.M., 1995. Stress and cognitive function. Current opinion in neurobiology 5, 205-216.

McEwen, B.S., Wingfield, J.C., 2010. What is in a name? Integrating homeostasis, allostasis and stress. Hormones and behavior 57, 105-111. 
McLennan, A.K., Ulijaszek, S.J., 2018. Beware the medicalisation of loneliness. Lancet (London, England) 391, 1480.

Meaney, M.J., Aitken, D.H., Sharma, S., Viau, V., 1992. Basal ACTH, corticosterone and corticosteronebinding globulin levels over the diurnal cycle, and age-related changes in hippocampal type I and type II corticosteroid receptor binding capacity in young and aged, handled and nonhandled rats. Neuroendocrinology 55, 204-213.

Mendes de Leon, C.F., Glass, T.A., Beckett, L.A., Seeman, T.E., Evans, D.A., Berkman, L.F., 1999. Social networks and disability transitions across eight intervals of yearly data in the New Haven EPESE. The journals of gerontology. Series B, Psychological sciences and social sciences 54, S162-172.

Menec, V.H., Newall, N.E., Mackenzie, C.S., Shooshtari, S., Nowicki, S., 2020. Examining social isolation and loneliness in combination in relation to social support and psychological distress using Canadian Longitudinal Study of Aging (CLSA) data. PloS one 15, e0230673.

Merrett, D.L., Kirkland, S.W., Metz, G.A., 2010. Synergistic effects of age and stress in a rodent model of stroke. Behavioural brain research 214, 55-59.

Metz, G.A., 2007. Stress as a modulator of motor system function and pathology. Reviews in the neurosciences 18, 209-222.

Mikosz, M., Nowak, A., Werka, T., Knapska, E., 2015. Sex differences in social modulation of learning in rats. Scientific reports $5,18114$.

Misiak, B., 2019. Stress, Allostatic Load, and Psychosis: One Step Forward in Research But Where to Go Next? Frontiers in psychiatry 10, 937.

Molton, I.R., Yorkston, K.M., 2017. Growing Older With a Physical Disability: A Special Application of the Successful Aging Paradigm. The journals of gerontology. Series B, Psychological sciences and social sciences 72, 290-299.

*Mottolese, R., Redouté, J., Costes, N., Le Bars, D., Sirigu, A., 2014. Switching brain serotonin with oxytocin. Proceedings of the National Academy of Sciences of the United States of America 111, 86378642.

Mozaffarian, D., Mande, J., Micha, R., 2019. Food Is Medicine-The Promise and Challenges of Integrating Food and Nutrition Into Health Care. JAMA internal medicine 179, 793-795.

*Musich, S., Wang, S.S., Kraemer, S., Hawkins, K., Wicker, E., 2018. Purpose in Life and Positive Health Outcomes Among Older Adults. Population health management 21, 139-147.

Mychasiuk, R., Gibb, R., Kolb, B., 2011. Prenatal bystander stress induces neuroanatomical changes in the prefrontal cortex and hippocampus of developing rat offspring. Brain research 1412, 55-62.

Ng, A., Tam, W.W., Zhang, M.W., Ho, C.S., Husain, S.F., McIntyre, R.S., Ho, R.C., 2018. IL-1beta, IL-6, TNFalpha and CRP in Elderly Patients with Depression or Alzheimer's disease: Systematic Review and MetaAnalysis. Scientific reports 8, 12050. 
Ngun, T.C., Ghahramani, N., Sanchez, F.J., Bocklandt, S., Vilain, E., 2011. The genetics of sex differences in brain and behavior. Frontiers in neuroendocrinology 32, 227-246.

Nicholson, N.R., 2012. A review of social isolation: an important but underassessed condition in older adults. The journal of primary prevention 33, 137-152.

*Nikolich-Žugich, J., 2018. The twilight of immunity: emerging concepts in aging of the immune system. Nature immunology 19, 10-19.

Niu, L., Jia, C., Ma, Z., Wang, G., Sun, B., Zhang, D., Zhou, L., 2020. Loneliness, hopelessness and suicide in later life: a case-control psychological autopsy study in rural China. Epidemiology and psychiatric sciences 29, e119.

Noorlander, C.W., De Graan, P.N., Middeldorp, J., Van Beers, J.J., Visser, G.H., 2006. Ontogeny of hippocampal corticosteroid receptors: effects of antenatal glucocorticoids in human and mouse. The Journal of comparative neurology 499, 924-932.

*O'Donnell, K., Badrick, E., Kumari, M., Steptoe, A., 2008. Psychological coping styles and cortisol over the day in healthy older adults. Psychoneuroendocrinology 33, 601-611.

*Olff, M., Frijling, J.L., Kubzansky, L.D., Bradley, B., Ellenbogen, M.A., Cardoso, C., Bartz, J.A., Yee, J.R., van Zuiden, M., 2013. The role of oxytocin in social bonding, stress regulation and mental health: an update on the moderating effects of context and interindividual differences. Psychoneuroendocrinology 38, 1883-1894.

Olson, D.M., Severson, E.M., Verstraeten, B.S., Ng, J.W., McCreary, J.K., Metz, G.A., 2015. Allostatic Load and Preterm Birth. International journal of molecular sciences 16, 29856-29874.

Onder, G., Rezza, G., Brusaferro, S., 2020. Case-Fatality Rate and Characteristics of Patients Dying in Relation to COVID-19 in Italy. Jama.

Ormstad, H., Eilertsen, G., Heir, T., Sandvik, L., 2020. Personality traits and the risk of becoming lonely in old age: A 5-year follow-up study. Health and quality of life outcomes 18, 47.

Ouanes, S., Popp, J., 2019. High Cortisol and the Risk of Dementia and Alzheimer's Disease: A Review of the Literature. Frontiers in aging neuroscience 11, 43.

Oyola, M.G., Handa, R.J., 2017. Hypothalamic-pituitary-adrenal and hypothalamic-pituitary-gonadal axes: sex differences in regulation of stress responsivity. Stress (Amsterdam, Netherlands) 20, 476-494.

*Palchykov, V., Kaski, K., Kertesz, J., Barabasi, A.L., Dunbar, R.I., 2012. Sex differences in intimate relationships. Scientific reports 2, 370.

Pantell, M., Rehkopf, D., Jutte, D., Syme, S.L., Balmes, J., Adler, N., 2013. Social isolation: a predictor of mortality comparable to traditional clinical risk factors. American journal of public health 103, 20562062. 
Papanicolaou, D.A., Wilder, R.L., Manolagas, S.C., Chrousos, G.P., 1998. The pathophysiologic roles of interleukin-6 in human disease. Annals of internal medicine 128, 127-137.

Pedersen, M., Bruunsgaard, H., Weis, N., Hendel, H.W., Andreassen, B.U., Eldrup, E., Dela, F., Pedersen, B.K., 2003. Circulating levels of TNF-alpha and IL-6-relation to truncal fat mass and muscle mass in healthy elderly individuals and in patients with type- 2 diabetes. Mechanisms of ageing and development 124, 495-502.

*Petersen, J., Kaye, J., Jacobs, P.G., Quinones, A., Dodge, H., Arnold, A., Thielke, S., 2016. Longitudinal Relationship Between Loneliness and Social Isolation in Older Adults: Results From the Cardiovascular Health Study. Journal of aging and health 28, 775-795.

Pikhartova, J., Bowling, A., Victor, C., 2014. Does owning a pet protect older people against loneliness? BMC geriatrics 14, 106.

Protection, C.f.D.C.a., 2020. Severe Outcomes Among Patients with Coronavirus Disease 2019 (COVID19) - United States, February 12-March 16, 2020. MMWR Morb Mortal Wkly Rep 2020 69, 343-346.

Rea, I.M., Gibson, D.S., McGilligan, V., McNerlan, S.E., Alexander, H.D., Ross, O.A., 2018. Age and AgeRelated Diseases: Role of Inflammation Triggers and Cytokines. Frontiers in immunology 9, 586.

*Read, S., Grundy, E., 2014. Allostatic load and health in the older population of England: a crossedlagged analysis. Psychosomatic medicine 76, 490-496.

Reblin, M., Uchino, B.N., 2008. Social and emotional support and its implication for health. Current opinion in psychiatry $21,201-205$.

Richardson, H., Lisandrelli, G., Riobueno-Naylor, A., Saxe, R., 2018. Development of the social brain from age three to twelve years. Nature communications 9, 1027.

*Rimmele, U., Hediger, K., Heinrichs, M., Klaver, P., 2009. Oxytocin makes a face in memory familiar. The Journal of neuroscience : the official journal of the Society for Neuroscience 29, 38-42.

Rodriguez-Artalejo, F., Guallar-Castillon, P., Herrera, M.C., Otero, C.M., Chiva, M.O., Ochoa, C.C., Banegas, J.R., Pascual, C.R., 2006. Social network as a predictor of hospital readmission and mortality among older patients with heart failure. Journal of cardiac failure 12, 621-627.

Rong, Y.D., Bian, A.L., Hu, H.Y., Ma, Y., Zhou, X.Z., 2018. Study on relationship between elderly sarcopenia and inflammatory cytokine IL-6, anti-inflammatory cytokine IL-10. BMC geriatrics 18, 308. Saito, T., Kai, I., Takizawa, A., 2012. Effects of a program to prevent social isolation on loneliness, depression, and subjective well-being of older adults: a randomized trial among older migrants in Japan. Archives of gerontology and geriatrics 55, 539-547.

Sapolsky, R.M., 2000. Stress hormones: good and bad. Neurobiology of disease 7, 540-542.

Sapolsky, R.M., Krey, L.C., McEwen, B.S., 1986. The neuroendocrinology of stress and aging: the glucocorticoid cascade hypothesis. Endocrine reviews 7, 284-301. 
Schmalzle, R., Brook O'Donnell, M., Garcia, J.O., Cascio, C.N., Bayer, J., Bassett, D.S., Vettel, J.M., Falk, E.B., 2017. Brain connectivity dynamics during social interaction reflect social network structure. Proceedings of the National Academy of Sciences of the United States of America 114, 5153-5158.

*Seeman, T.E., McEwen, B.S., Rowe, J.W., Singer, B.H., 2001. Allostatic load as a marker of cumulative biological risk: MacArthur studies of successful aging. Proceedings of the National Academy of Sciences of the United States of America 98, 4770-4775.

Seltzer, L.J., Ziegler, T.E., Pollak, S.D., 2010. Social vocalizations can release oxytocin in humans. Proceedings. Biological sciences 277, 2661-2666.

Shaw, B.A., Krause, N., Liang, J., Bennett, J., 2007. Tracking changes in social relations throughout late life. The journals of gerontology. Series B, Psychological sciences and social sciences 62, 590-99.

Simon, A.K., Hollander, G.A., McMichael, A., 2015. Evolution of the immune system in humans from infancy to old age. Proceedings. Biological sciences 282, 20143085.

Sippel, L.M., R. H. Pietrzak, D. S. Charney, L. C. Mayes, and S. M. Southwick., 2015a. How does social support enhance resilience in the trauma-exposed individual?. Ecology and Society 20.

Sippel, L.M., R. H. Pietrzak, D. S. Charney, L. C. Mayes, and S. M. Southwick., 2015b. How does social support enhance resilience in the trauma-exposed individual? Ecology and Society 20.

Slotkin, T.A., Seidler, F.J., Wood, C.R., Lau, C., 2008. Development of glucocorticoid receptor regulation in the rat forebrain: implications for adverse effects of glucocorticoids in preterm infants. Brain research bulletin 76, 531-535.

Smith, L.K., Jadavji, N.M., Colwell, K.L., Katrina Perehudoff, S., Metz, G.A., 2008. Stress accelerates neural degeneration and exaggerates motor symptoms in a rat model of Parkinson's disease. The European journal of neuroscience 27, 2133-2146.

Sohn, E., 2018. How the evidence stacks up for preventing Alzheimer's disease. Nature 559, S18-s20. Stack, A., Carrier, N., Dietz, D., Hollis, F., Sorenson, J., Kabbaj, M., 2010. Sex differences in social interaction in rats: role of the immediate-early gene zif268. Neuropsychopharmacology : official publication of the American College of Neuropsychopharmacology 35, 570-580.

Steptoe, A., Fancourt, D., 2019. Leading a meaningful life at older ages and its relationship with social engagement, prosperity, health, biology, and time use. Proceedings of the National Academy of Sciences of the United States of America 116, 1207-1212.

*Steptoe, A., Shankar, A., Demakakos, P., Wardle, J., 2013. Social isolation, loneliness, and all-cause mortality in older men and women. Proceedings of the National Academy of Sciences of the United States of America 110, 5797-5801.

Stern, Y., 2006. Cognitive reserve and Alzheimer disease. Alzheimer disease and associated disorders 20, S69-74. 
Szell, M., Thurner, S., 2013. How women organize social networks different from men. Scientific reports 3, 1214.

Takahashi, K., Kamide, N., Suzuki, M., Fukuda, M., 2016. Quality of life in people with Parkinson's disease: the relevance of social relationships and communication. Journal of physical therapy science 28 , 541-546.

*Tampubolon, G., Maharani, A., 2018. Trajectories of allostatic load among older Americans and Britons: longitudinal cohort studies. BMC geriatrics 18, 255.

*Tanskanen, J., Anttila, T., 2016. A Prospective Study of Social Isolation, Loneliness, and Mortality in Finland. American journal of public health 106, 2042-2048.

Taylor, S.E., 2010. Mechanisms linking early life stress to adult health outcomes. Proceedings of the National Academy of Sciences of the United States of America 107, 8507-8512.

*Theodoridou, A., Rowe, A.C., Penton-Voak, I.S., Rogers, P.J., 2009. Oxytocin and social perception: oxytocin increases perceived facial trustworthiness and attractiveness. Hormones and behavior $56,128-$ 132.

*Tobin, S.S., Neugarten, B.L., 1961. Life satisfaction and social interaction in the aging. Journal of gerontology 16, 344-346.

Toescu, E.C., 2013. Neuroendocrine Theory of Aging, in: Gellman, M.D., Turner, J.R. (Eds.), Encyclopedia of Behavioral Medicine. Springer New York, New York, NY, pp. 1311-1315.

Trainor, B.C., Pride, M.C., Villalon Landeros, R., Knoblauch, N.W., Takahashi, E.Y., Silva, A.L., Crean, K.K., 2011. Sex differences in social interaction behavior following social defeat stress in the monogamous California mouse (Peromyscus californicus). PloS one 6, e17405.

Tsai, H.H., Tsai, Y.F., Wang, H.H., Chang, Y.C., Chu, H.H., 2010. Videoconference program enhances social support, loneliness, and depressive status of elderly nursing home residents. Aging \& mental health 14 , 947-954.

Uchino, B.N., Cawthon, R.M., Smith, T.W., Light, K.C., McKenzie, J., Carlisle, M., Gunn, H., Birmingham, W., Bowen, K., 2012. Social relationships and health: is feeling positive, negative, or both (ambivalent) about your social ties related to telomeres? Health psychology : official journal of the Division of Health Psychology, American Psychological Association 31, 789-796.

Ullmann, E., Perry, S.W., Licinio, J., Wong, M.L., Dremencov, E., Zavjalov, E.L., Shevelev, O.B., Khotskin, N.V., Koncevaya, G.V., Khotshkina, A.S., Moshkin, M.P., Lapshin, M.S., Komelkova, M.V., Feklicheva, I.V., Tseilikman, O.B., Cherkasova, O.P., Bhui, K.S., Jones, E., Kirschbaum, C., Bornstein, S.R., Tseilikman, V., 2019. From Allostatic Load to Allostatic State-An Endogenous Sympathetic Strategy to Deal With Chronic Anxiety and Stress? Frontiers in behavioral neuroscience 13, 47.

Valtorta, N., Hanratty, B., 2012. Loneliness, isolation and the health of older adults: do we need a new research agenda? Journal of the Royal Society of Medicine 105, 518-522. 
Vamvakopoulos, N.V., 1995. Sexual dimorphism of stress response and immune/ inflammatory reaction: the corticotropin releasing hormone perspective. Mediators of inflammation 4, 163-174.

van der Voorn, B., Hollanders, J.J., Ket, J.C.F., Rotteveel, J., Finken, M.J.J., 2017. Gender-specific differences in hypothalamus-pituitary-adrenal axis activity during childhood: a systematic review and meta-analysis. Biology of sex differences 8,3 .

Ventura, M.T., Casciaro, M., Gangemi, S., Buquicchio, R., 2017. Immunosenescence in aging: between immune cells depletion and cytokines up-regulation. Clinical and molecular allergy : CMA 15, 21.

Verity, R., Okell, L.C., Dorigatti, I., Winskill, P., Whittaker, C., Imai, N., Cuomo-Dannenburg, G., Thompson, H., Walker, P.G.T., Fu, H., Dighe, A., Griffin, J.T., Baguelin, M., Bhatia, S., Boonyasiri, A., Cori, A., Cucunuba, Z., FitzJohn, R., Gaythorpe, K., Green, W., Hamlet, A., Hinsley, W., Laydon, D., NedjatiGilani, G., Riley, S., van Elsland, S., Volz, E., Wang, H., Wang, Y., Xi, X., Donnelly, C.A., Ghani, A.C., Ferguson, N.M., 2020. Estimates of the severity of coronavirus disease 2019: a model-based analysis. The Lancet. Infectious diseases.

Verstraeten, B.S.E., McCreary, J.K., Falkenberg, E.A., Fang, X., Weyers, S., Metz, G.A.S., Olson, D.M., 2019a. Multiple prenatal stresses increase sexual dimorphism in adult offspring behavior.

Psychoneuroendocrinology 107, 251-260.

Verstraeten, B.S.E., McCreary, J.K., Weyers, S., Metz, G.A.S., Olson, D.M., 2019b. Prenatal two-hit stress affects maternal and offspring pregnancy outcomes and uterine gene expression in rats: match or mismatch? Biology of reproduction 100, 195-207.

Ward, J.B., Albrecht, S.S., Robinson, W.R., Pence, B.W., Maselko, J., Haan, M.N., Aiello, A.E., 2018. Neighborhood language isolation and depressive symptoms among elderly U.S. Latinos. Annals of epidemiology 28, 774-782.

Warren, N., Sakellariou, D., 2020. Neurodegeneration and the Intersubjectivities of Care. Medical anthropology 39, 1-15.

Weiss, E.L., Longhurst, J.G., Mazure, C.M., 1999. Childhood sexual abuse as a risk factor for depression in women: psychosocial and neurobiological correlates. The American journal of psychiatry 156, 816-828.

*Yang, Y.C., Boen, C., Gerken, K., Li, T., Schorpp, K., Harris, K.M., 2016. Social relationships and physiological determinants of longevity across the human life span. Proceedings of the National Academy of Sciences of the United States of America 113, 578-583.

Yang, Y.C., Schorpp, K., Harris, K.M., 2014. Social support, social strain and inflammation: evidence from a national longitudinal study of U.S. adults. Social science \& medicine (1982) 107, 124-135.

Yao, Y., Robinson, A.M., Zucchi, F.C., Robbins, J.C., Babenko, O., Kovalchuk, O., Kovalchuk, I., Olson, D.M., Metz, G.A., 2014. Ancestral exposure to stress epigenetically programs preterm birth risk and adverse maternal and newborn outcomes. BMC medicine 12, 121. 
Yiallouris, A., Tsioutis, C., Agapidaki, E., Zafeiri, M., Agouridis, A.P., Ntourakis, D., Johnson, E.O., 2019. Adrenal Aging and Its Implications on Stress Responsiveness in Humans. Frontiers in endocrinology 10, 54.

Yuan, M., Wu, N.C., Zhu, X., Lee, C.D., So, R.T.Y., Lv, H., Mok, C.K.P., Wilson, I.A., 2020. A highly conserved cryptic epitope in the receptor binding domains of SARS-CoV-2 and SARS-CoV. Science (New York, N.Y.) 368, 630-633.

Zamir, S., Hennessy, C.H., Taylor, A.H., Jones, R.B., 2018. Video-calls to reduce loneliness and social isolation within care environments for older people: an implementation study using collaborative action research. BMC geriatrics 18, 62.

Zethraeus, N., Kocoska-Maras, L., Ellingsen, T., von Schoultz, B., Hirschberg, A.L., Johannesson, M., 2009. A randomized trial of the effect of estrogen and testosterone on economic behavior. Proceedings of the National Academy of Sciences of the United States of America 106, 6535-6538.

Zsoldos, E., Filippini, N., Mahmood, A., Mackay, C.E., Singh-Manoux, A., Kivimäki, M., Jenkinson, M., Ebmeier, K.P., 2018. Allostatic load as a predictor of grey matter volume and white matter integrity in old age: The Whitehall II MRI study. Scientific reports 8, 6411. 